\section{OAK RIDGE NATIONAL LABORATORY}

manotur makeforta
Characterization of Uranium Contaminated Soils from DOE Fernald Environmental Management Project Site: Results of Phase I Characterization

\author{
S. Y. Lee \\ J. D. Marsh, Jr
}


This report has been reproduced directly from the best available copy.

Available to DOE and DOE contractors from the Office of Scientific and Technical Information, P.O. Box 62, Oak Ridge, TN 37831; prices available from (615) 576-8401, FTS 626-8401.

Avallable to the public from the National Technical Information Service, U.S. Department of Commerce, 5285 Port Royal Rd., Springfield, VA 22161.

This repor: was prepared as an account of work sponsored by an agency of t/1e United States Government. Neither the United States Government nor any agency thereof, nor any of their employees, makes any warranty, express or implied, or assumes any legal liability or responsibility for the accuracy, completeness, or usefulness of any information, apparatus, product, or process disclosed, or represents that its use would not infringe privately owned rights. Reference herein to any specific commercial product, process, or service by trade name, trademark, manufacturer, or otherwise, does not necessarily constitute or imply its endorsement, recommendation, or favoring by the United States Government or any agency thereof. The views and opinions of authors expressed herein do not necessarily state or reflect those of the United States Government or any agency thereof. 


\title{
CHARACTERIZATION OF URANIUM CONTAMINATED SOILS FROM DOE FERNALD ENVIRONMENTAL MANAGEMENT PROJECT SITE: RESULTS OF PHASE I CHARACTERIZATION
}

\author{
S. Y. Lee \\ J. D. Marsh, Jr. \\ Environmental Sciences Division \\ Publication No. 3786 \\ Date Published - January 1992 \\ with \\ Characterization Group \\ Integrated Demonstration \\ Vincent Tidwell (SNL), Group Leader \\ James Cunnane (ANL) S. Y. Lee (ORNL) Vic Gil (FEMP) \\ Mark Nichelson (HAZWRAP) Dale Perry (LBL) \\ Prepared for the \\ FEMP Uranium in Contaminated Soils ID \\ Westinghouse Environmental Management Company of Ohio \\ and \\ Office of Technology Development \\ (61 3078801 ) \\ Prepared by the \\ OAK RIDGE NATIONAL LABORATORY \\ Oak Ridge, Tennessee 37831 \\ managed by \\ MARTIN MARIETTA ENERGY SYSTEMS, INC. \\ for the \\ U.S. DEPARTMENT OF ENERGY \\ under contract DE-AC05-84OR21400
}


LIST OF FIGURES $\ldots \ldots \ldots \ldots \ldots \ldots \ldots \ldots \ldots \ldots \ldots \ldots \ldots \ldots \ldots$

LIST OF TABLES $\ldots \ldots \ldots \ldots \ldots \ldots \ldots \ldots \ldots \ldots \ldots \ldots \ldots \ldots \ldots \ldots$

ACKNOWLEDGEMENTS $\ldots \ldots \ldots \ldots \ldots \ldots \ldots \ldots \ldots \ldots \ldots \ldots \ldots \ldots$

ABSTRACT $\ldots \ldots \ldots \ldots \ldots \ldots \ldots \ldots \ldots \ldots \ldots \ldots \ldots \ldots \ldots \ldots \ldots \ldots \ldots \ldots \ldots$

INTRODUCTION $\ldots \ldots \ldots \ldots \ldots \ldots \ldots \ldots \ldots \ldots \ldots \ldots \ldots \ldots \ldots \ldots$

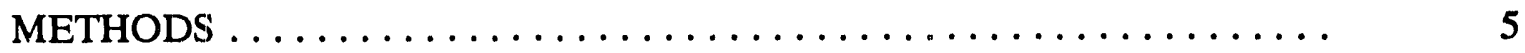

RESULTS AND DISCUSSION $\ldots \ldots \ldots \ldots \ldots \ldots \ldots \ldots \ldots \ldots \ldots \ldots \ldots$

Soil Description and Gamma Spectroscopic Analysis ............ 11

Reference Soils $\ldots \ldots \ldots \ldots \ldots \ldots \ldots \ldots \ldots \ldots \ldots \ldots \ldots \ldots \ldots \ldots$

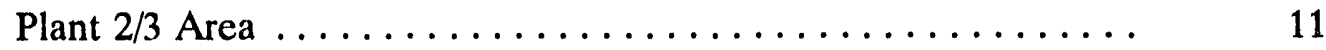

Plant 1 Drum Storage Area $\ldots \ldots \ldots \ldots \ldots \ldots \ldots \ldots \ldots$

Decontamination Pad/Drum Baling Area ............. 14

Plant 6 Area $\ldots \ldots \ldots \ldots \ldots \ldots \ldots \ldots \ldots \ldots \ldots \ldots \ldots \ldots \ldots \ldots \ldots$

Incinerator Area $\ldots \ldots \ldots \ldots \ldots \ldots \ldots \ldots \ldots \ldots \ldots \ldots \ldots \ldots \ldots$

Soil Particle Size Distributions $\ldots \ldots \ldots \ldots \ldots \ldots \ldots \ldots \ldots \ldots \ldots \ldots$

Uranium Distribution with Particle Size in Soils . . . . . . . . 25

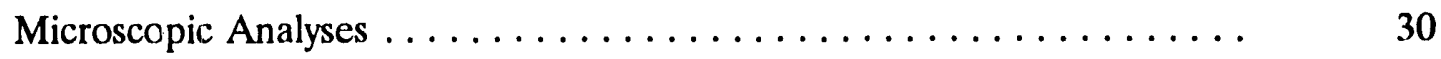

Heavy Liquid Separation $\ldots \ldots \ldots \ldots \ldots \ldots \ldots \ldots \ldots \ldots \ldots \ldots \ldots$

Mineralogical Analyses . . . . . . . . . . 32

Chemical Leaching Experiments $\ldots \ldots \ldots \ldots \ldots \ldots \ldots \ldots \ldots \ldots \ldots$

SUMMARY AND RECOMMENDATIONS ............... 34 
Selection of Contaminated Soils for Use in Treatability Studies and Demonstration Areas

Plant 2/3 Area

Plant 1 Drum Storage Area

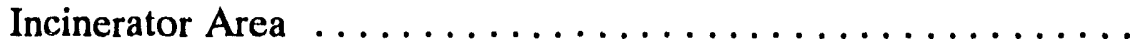

Preliminary Screening of Integrated Technology . . . . . . . . . . 37

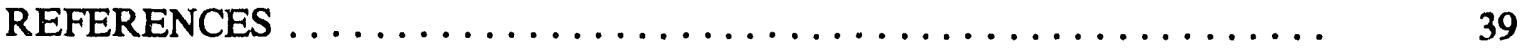

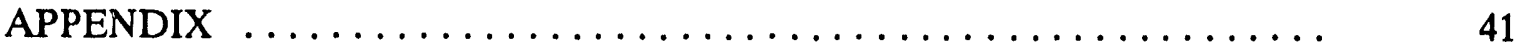

Plate 1. SEM and EDX of uranium-containing particles from SP2

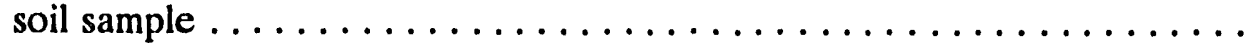

Plate 2. SEM and EDX of uranium-containing particles from SP4

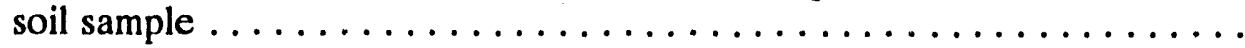

Plate 3. SEM and DDX of uranium-containing particles from SP5

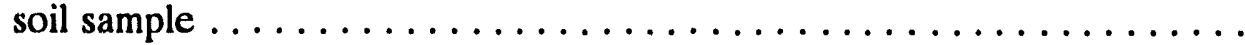

Plate 4. SEM and DDX of uranium-containing particles from SP8

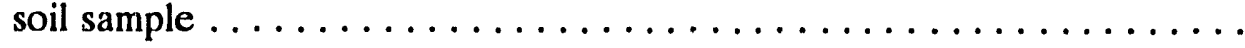

Plate 5. SEM and EDX of uranium-containing particles from SP9

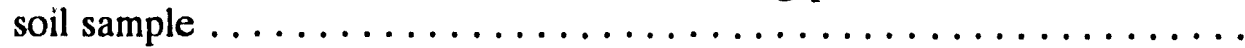




\section{LIST OF FIGURES}

Figure

Page

1 Sampling locations in Operable Unit 3 of Fernald

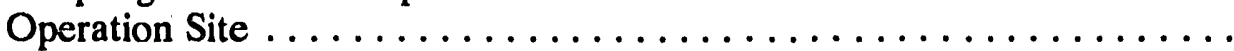

2 Sampling locations in the incinerator area of

Fernald Operation Site $\ldots \ldots \ldots \ldots \ldots \ldots \ldots \ldots \ldots$

3 Reference soil sampling locations on soil survey

map of Hamilton County, Ohio (FdA = Fincastle Series;

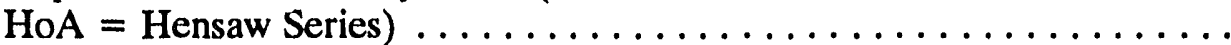

4 XRD of clay fractions of SP4-1A/2A and Henshaw soils 


\section{LIST OF TABLES}

Table

Page

1. Characterization information needs for the Integrated

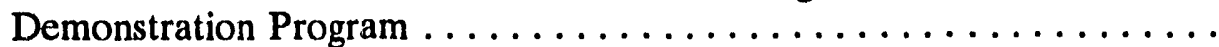

2. Radionuclide concentrations in reference soils at varying depths .....

3. Radionuclide concentrations in SP1 soil core samples at

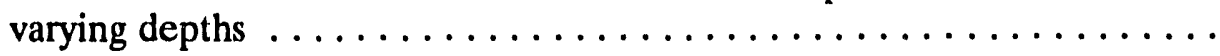

4. Radionuclide concentrations in SP2 soil core samples at varying depths

5. Radionuclide concentrations in SP3 soil core samples at varying depths

6. Radionuclide concentrations in SP4 soil core samples at

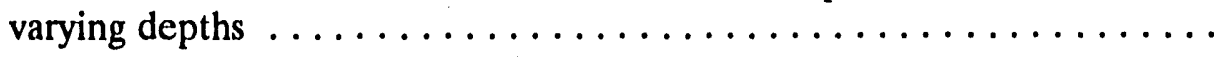

7. Radionuclide concentrations in SP5 soil core samples at

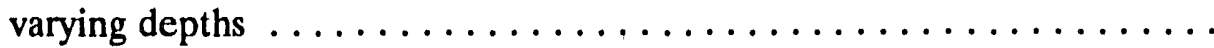

8. Radionuclide concentrations in SP6 soil core samples at

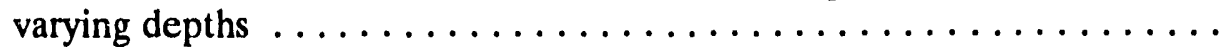

9. Radionuclide concentrations in SP7 soil core samples at

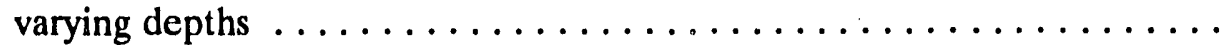

10. Radionuclide concentrations in SP8 soil core samples at

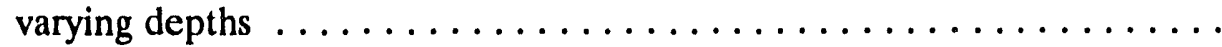

11. Radionuclide concentrations in SP9 soil core samples at

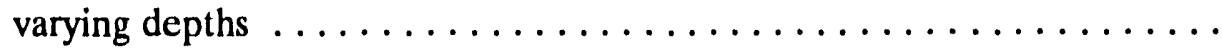

12. Radionuclide concentrations in SP10 soil core samples at varying depths $\ldots \ldots \ldots \ldots \ldots \ldots \ldots \ldots \ldots \ldots \ldots \ldots \ldots \ldots \ldots \ldots \ldots$

13. Soil particle size distribution and uranium distribution with particle size of the soil samples $\ldots \ldots \ldots \ldots \ldots \ldots \ldots \ldots$

14. $\mathrm{pH}$ measurements of contaminated and reference soils $\ldots \ldots \ldots \ldots \ldots$

15. Uranium, cations, and anions dissolved during particle size separation. 
16. Weight and uranium distribution of sand-size fractions after heavy liquid density separation in lithium metatungstate solution with a density $2.8 \mathrm{~g} / \mathrm{mL}$

17. Percent extractable uranium and total uranium concentrations 


\section{ACKNOWLEDGMENTS}

The authors wish to thank the following individuals for their assistance:

D. P. Hoffmann, G. C. Marsh, R. C. Melton, and H. M. Henson, Quality and Technology Service Division, K-25, for coordination of sample preparation and scanning electron microscopic analyses; and soil sampling group of Westinghouse Environmental Management Company of Ohio for site selection and soil core sampling. We also appreciate the administrative and management support given to us by $\mathrm{M}$. Thompson and Kim Nuhfer, Technology Demonstration, Westinghouse Environmental Management Company of Ohio. 


\begin{abstract}
LEE, S. Y. and J. D. MARSH, Jr. 1992. Characterization of uranium contaminated soils from DOE Fernald Environmental Management Project Site: Results of Phase I characterization. ORNL/TM-11980. Oak Ridge National Laboratory, Oak Ridge, Tennessee. 70 pp.
\end{abstract}

The Integrated Demonstration (ID) for remediation of uranium-contaminated soils has been established by the DOE Office of Technology Development. The Fernald site was selected as the DOE facility for the field demonstration. The principle objective of this ID is to evaluate and compare the versatility, efficiency, and economics of various technologies that may be combined into systems for the removal of uranium from contaminated soils.

The ID Characterization Task group designed a study to obtain basic information relating to soil properties and the nature of uranium contamination at the site soil. Such information is essential for the selection of (1) contaminated soils for use in treatability studies, (2) a field demonstration area at the site, and (3) integrated technologies. The task group selected five areas and collected two core samples from each area.

The nature of soil contamination was investigated by examining (1) uranium distribution with soil depth, (2) soil particle size distributions and their uranium contribution, (3) soil chemical and physical properties, (4) particle density of soil and contaminant, (5) mineralogical and microscopic properties of soil and contaminant, (5) chemical leaching characteristics, and (6) background soil uranium content and soil properties.

The results indicated: (1) except in an area contaminated by acidic solution spills, the contamination depth of most areas was shallow (usually $<10 \mathrm{~cm}$ containing from 10 to $2800 \mathrm{pCi} / \mathrm{g}$ ); (2) background uranium concentration of off-site soils was $<4 \mathrm{pCi} / \mathrm{g}$; (3) the sand and silt size fraction of soils contained from 48 to $79 \%$ of the uranium in soils;

(4) the dominant form of uranium was sand and silt-sized particulate often associated with 
calcium, phosphorous, iron, and silicon; (5) most of the uranium particulates had a density $>2.9 \mathrm{~g} / \mathrm{mL}$, however; and (6) considerable amounts of soil uranium, 10 to $49 \%$ and 20 to $75 \%$, could be extracted using $2 \%$ solutions of ammonium carbonate and citric acid, respectively.

On the basis of the soil characterization results, two areas, Plant 1 Drum Storage area and the Incinerator area, were selected for use in treatability studies and insitu characterization demonstration areas. The Plant 1 Drum Storage area was contaminated by uranium product spills and the Incinerator area was contaminated by airborne uranium materials during incineration of contaminated materials. Particulate uranium was the dominant form associated with the sand and silt fractions of both soils (see attached micrograph plate). Some uranium in the soils was not readily extractable. Therefore, simple chemical extraction alone would not be effective for waste volume reduction as soil remediation. Development of more effective and selective extraction technology and density-based physical separation technology is needed to meet the cleanup goal for the Integrated Demonstration. 


\title{
CHARACTERIZATION OF URANIUM-CONTAMINATED SOILS \\ FROM DOE FERNALD \\ ENVIRONMENTAL MANAGEMENT PROJECT SITE: \\ RESULTS OF PHASE I CHARACTERIZATION
}

\author{
S. Y. LEE AND J. D. MARSH, JR. \\ Environmental Sciences Division \\ Oak Ridge National Laboratory
}

\section{INTRODUCTION}

The Integrated Demonstration (ID) for uranium-contaminated soils remediation has been established by the DOE Office of Technology Development. The principle objective of this ID is to evaluate and compare the versatility, efficiency, and economics of various technologies that may be combined into systems for the removal of uranium from contaminated soils. Because the scope of the ID program is to address remedial alternatives for uranium-contaminated soils, the Fernald Site was selected as the DOE facility for the field demonstration. The draft RI/FS report (DOE, 1990) of the site concluded that the majority of uranium-contaminated soils were located within the Operable Unit 3, including the Sewage Treatment Plant/Old Incinerator area (Figs. 1 and 2). Therefore, the ID team selected Operable Unit 3 as the source of contaminated soils for the field demonstration (Note: After the renegotiation of the CERCLA Consent Agreement, the management of all soils became the responsibility of Operable Unit 5.)

The Phase I soil sampling/characterization task was established by the Characterization Group to obtain basic information related to soil properties and the nature of uranium contamination. Such information is essential for:

- the selection of contaminated soils for use in treatability studies,

- the selection of a field demonstration area or areas within Operable Unit 3, and

- the preliminary screening of integrated technologies (Tidwell's Memorandum, 1991). 


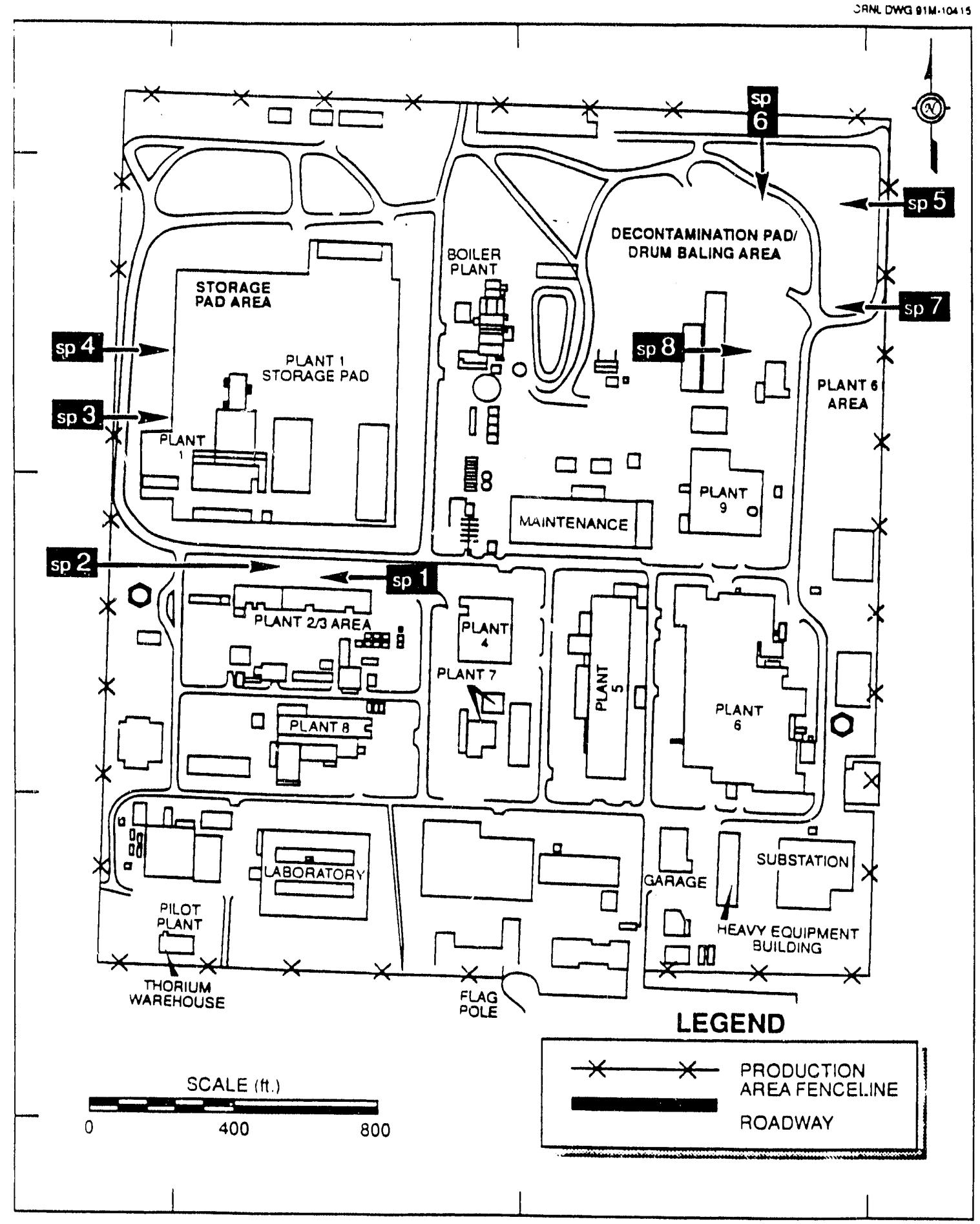

Figure 1. Sampling locations in Operable Unit 3 of Fernald Operation Site. 


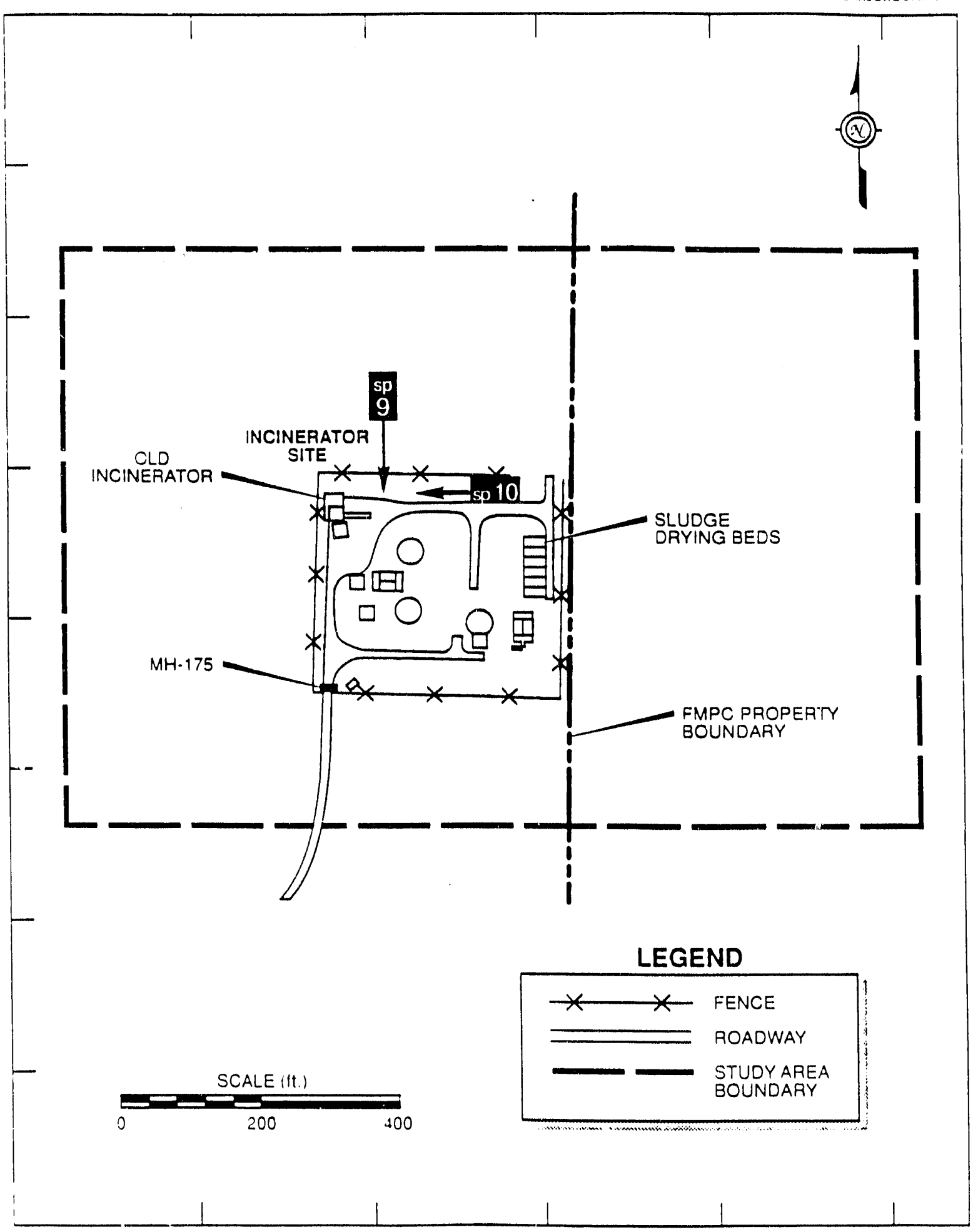

Figure 2. Sampling locations in the incinerator area of Fernald Operation Site. 
Table 1 is a list of the information needs. More detailed characterization will be conducted in the Phase II investigation that will follow the Phase I investigation. This Phase I investigation is intended to be finished within $21 / 2$ months because of the schedule established by DOE for preliminary treatability tests at Nevada.

This preliminary investigation will, however, provide critical information related to: (1) the nature of uranium contamination, (2) important soil propertics related to uranium retention, (3) guide the direction on the next phase of the investigation, and (4) narrow the scope of technology investigations.

Table 1. Characterization information needs for the Integrated Demonstration Program
Properties
Where the information is needed

1. Uranium distribution with depth:

Excavation, Risk assessment

2. Soil particle size distribution:

Treatability, Risk assessment, Waste Disposal

3. Uranium distribution with particle size: Treatability, Risk Assessment

4. Soil chemical and physical properties: Excavation, Treatability

5. Specific gravity soil/contaminant:

Treatability

6. Soil solution chemistry:

Treatability, Risk Assessment, Site Operation

7. Mineralogical analysis:

Treatability, Waste Disposal

8. Microscopic analysis:

Treatability

9. Uranium form identification:

Treatability, Risk Assessment

10. Chemical leaching test:

Treatability, Waste Disposal, Risk

Assessment

11. Reference soil characterization:

Risk Assessment, Treatability, Regulation

Characterization Group members agreed to select soil sampling areas based on the contamination source term characteristics, that is, aqueous uranium wastes, solid uranium product spills, and airborne uranium wastes (dust, acrosols) (Tidwell's Memorandum, 1991). The decontamination Pad/Drum Baling area and north of the Plant $2 / 3$ area have 
been selected to represent the soils contaminated by aqueous uranium wastes. The Plant 1 Drum Storage area was selected for the soils contaminated by uranium product spills. And, the Incinerator and Plant 6 areas were selected to represent the soils contaminated by airborne, releases of uranium. Two reference soils, Fincastle and Henshaw Series located about 1 mile and 1.5 miles west of the Fernald Site, respectively, were collected for base line datá establishment (Fig. 3).

\section{METHODS}

Collection of soil core samples for the Phase I Sampling Program was performed according to the protocols and procedures established for the RI/FS Operable Unit 3 program, the RI/FS Quality Assurance Project Plan, and the Project Specific Health and Safety Plan (Tidwell's Memorandum, 1991).

Characterization Group representatives (S. Y. Lee and Mark Nichelson) with the aid of the Fernald RI/FS sampling team and Health Physics personnel performed site surveys with a sodium-iodide survey meter at selected sampling sites. Specific sampling points were selected according to areas exhibiting a high activity. Prior to collecting sample, gravel or grass covers were removed before setting up a hand-driven auger. A stainless steel auger with one or three 12 -in.-long polybutyrate sleeve ( 2 in. diam) was used for sample collection. After retrieval of the auger by a hydraulic jack, soil cores were cut at the joints of sleeves and capped for shipment. Supplemental undisturbed samples were collected by pushing down an 8.5 -cm-diam $\times 3.5-\mathrm{cm}$-deep plastic dish and cutting the bottom of the soil block with a knife for microscopic analyses. Samples were shipped to the Oak Ridge National Laboratory for characterization.

The soil cores were described according to the standard soil description methodology (Soil Survey Staff, 1975) and then cut into 2- to 4-in. segments. Each soil core segment was given an identification number in the following way; SP\#-1-A, "SP\#" representing sampling site, " -1 " representing the order of sleeve from the top or the order of sampling when three 12-in. cores were taken instead of one 36 in. core per each sampling location, and " $-A^{\text {" }}$ representing the order of each soil segment starting from the top of each sleeve. 


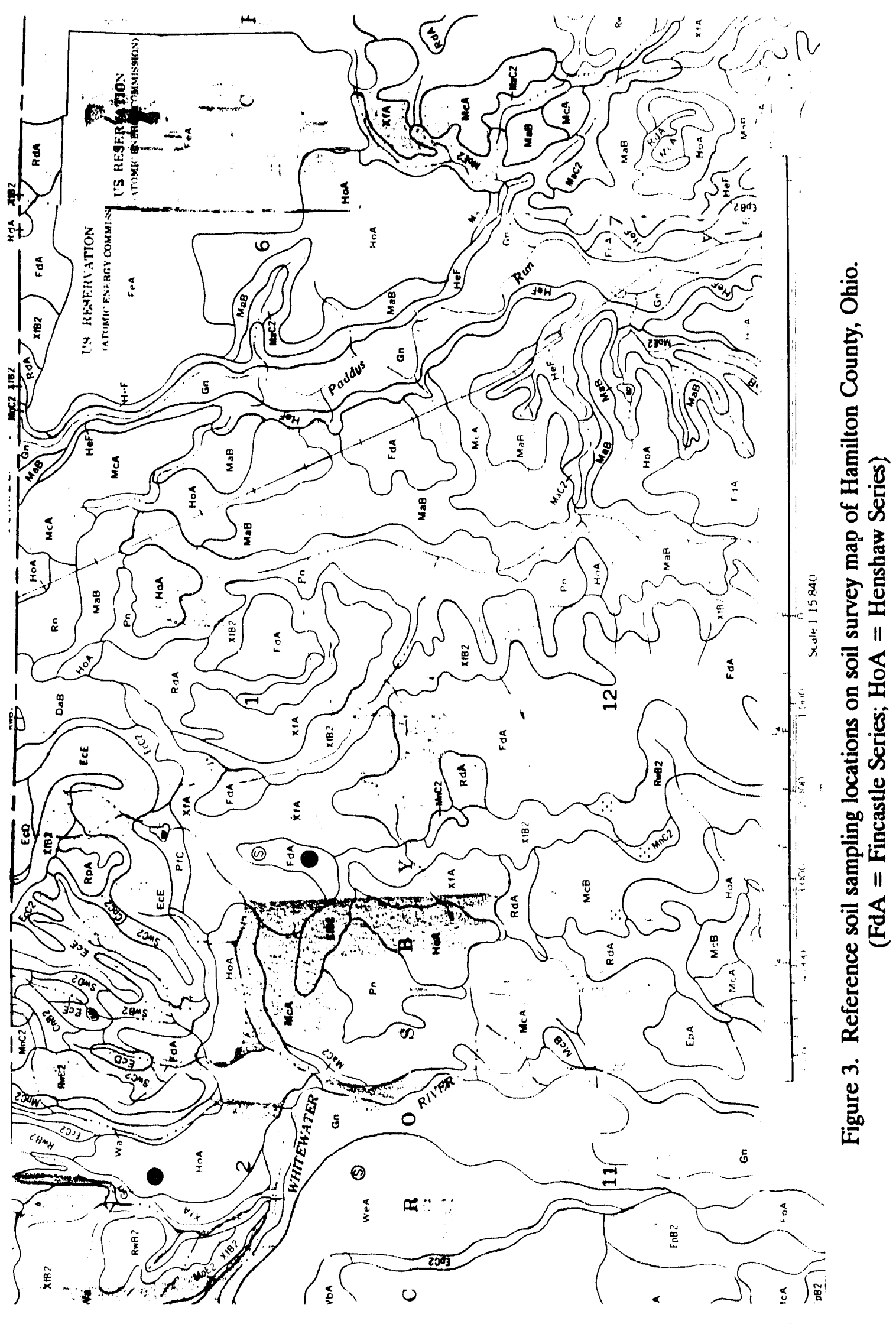


Soil pH measurements were made using a PHM 84 Research $\mathrm{pH}$ meter with a combination $\mathrm{pH}$ electrode. The meter and electrode were calibrated with standard $\mathrm{pH}$ buffers of $\mathrm{pH} 7$ and 10 to encompass the $\mathrm{pH}$ range of the soil samples. The soil samples were prepared by adding $5 \mathrm{ml}$ of distilled water to $5 \mathrm{~g}$ of soil, stirring, and allowing the soil and water to set in contact for about $6 \mathrm{~h}$ before beginning $\mathrm{pH}$ measurements. The electrode was left in the soil/water mixture until the reading had stabilized and the measurement recorded.

The soil core segments ( 3 to 4 in.) were transferred to $8.5-\mathrm{cm}$-diam (internal) by 3-cm-high plastic containers for gamma spectroscopy. Gamma analysis was done on all the samples prior to particle size separation. The samples were counted on a high resolution, solid state, coaxial, intrinsic, germanium (IG) detector coupled to an ND6700 multichannel analyzer with 4096 channels. The gamma system had previously been calibrated with a Amershan QCY44 certified mixed gamma standard with traceability to National Institute of Standards and Technology (NIST), formerly the National Bureau of Standards (NBS), in the geometry used to contain the soil samples. In addition, weekly and daily sources were counted to verify that the detectors were remained calibration. Samples were counted down the soil coiumn from $1 \mathrm{~h}$ to overnight depending on their level of activity. The ${ }^{238} \mathrm{U}$ concentration was determined using the $1001-\mathrm{keV}$ line for ${ }^{234} \mathrm{~Pa}$, which is a daughter of ${ }^{238} \mathrm{U}$ assumed to be in secular equilibrium with the uranium isotope. At equilibrium the activities of the two nuclides should be the same and the measurement of one determines the activity of the other. The ${ }^{235} \mathrm{U}$ was determined using its $143-\mathrm{keV}$ peak. The activity ratio of ${ }^{235} \mathrm{U} /{ }^{238} \mathrm{U}$ for natural uranium is 4.6. Cesium-137 at $661 \mathrm{keV}$ and ${ }^{40} \mathrm{~K}$ at $1460 \mathrm{keV}$ were also measured down the soil column. For those samples with activities below detectable levels, a minimum detectable activity (MDA) is reported. This is the minimum activity of the radionuclide which have to be present $95 \%$ of the time to be detected in the presence of the sample compton continuum.

After gamma spectroscopy, soil segments from the SP22, SP2-3, SP4, SP5, SP8, and SP9 cores were selected. The selected segments from each core were combined as needed to obtain enough sample for characterization. For example, a soil sample identification number such as SP2-2-ABC represents a mixed sample of $A, B$, and $C$ segments from the 
SP2-2 sleeve and SP4-1A/2A represents a mixed soil of the first segment of the first sleeve and the first segment of the second sleeve from SP4.

Particle size separation of the selected soil samples was performed by dry sieving with 4- and 2-mm sieves (size fractions larger than $2 \mathrm{~mm}$ were designated as gravel). The $<2-\mathrm{mm}$ fractions were further separated into 2 to $0.053 \mathrm{~mm}$ (sand), 0.053 to $0.002 \mathrm{~mm}$ (silt), and $<0.002 \mathrm{~mm}$ (clay) by wet sieving and centrifugation method (Jackson 1975). Water samples produced during particle-size separation and soil samples were submitted to the Environmental Analysis Laboratory located at the Y-12 Plant in Oak Ridge, Tennessee, for the following analyses; total uranium by mass spectroscopy, isotopic uranium by alpha spectroscopy, trace element analysis by inductively coupled plasma atomic emission spectroscopy (ICP-AES), anions by ion chromatography (IC), and alkalinity by acid titration to $\mathrm{pH} 4.5$. Due to the sensitivity of the alpha spectroscopy method for uranium, only those soils and leachates with very low levels of uranium ( $<10 \mathrm{pCi} / \mathrm{g}$ for solid and $<100 \mathrm{pCi} / \mathrm{L}$ for liquid) could be analyzed by this method. For this reason, the high-level uranium samples were done by mass spectroscopy. Prior to the uranium and metal analyses, 1 to $3 \mathrm{~g}$ of soil was digested at 90 to $95^{\circ} \mathrm{C}$ with nitric acid and $30 \%$ hydrogen peroxide, centrifuged, and filtered. The filtrates were diluted before spectroscopy analyses.

Several leaching solutions were employed to determine their effectiveness in extracting uranium from the soil. The extractants and their means of preparation were:

- $0.1 \mathrm{~N}$ nitric acid $\left[\mathrm{HNO}_{3}\right]: 6.25 \mathrm{~mL}$ of concentrated nitric acid was diluted to $1 \mathrm{~L}$ with distilled water.

- $2 \%$ ammonium carbonate [( $\left.\left.\mathrm{NH}_{4}\right)_{2} \mathrm{CO}_{3}\right]: 20 \mathrm{~g}$ of $\left(\mathrm{NH}_{4}\right)_{2} \mathrm{CO}_{3}$ was dissolved in distilled water and diluted to $1 \mathrm{~L}$.

- $5 \%$ sodium hypochlorite $(\mathrm{NaOCl}): 50 \mathrm{~mL}$ of $\mathrm{NaOCl}$ reagent $(\mathrm{Cl}<6 \%)$ was diluted to $1 \mathrm{~L}$ with distilled water.

- $0.1 \mathrm{M}$ ethylenediaminetetraacetic acid, disodium salt (EDTA): $37.224 \mathrm{~g}$ of EDTA was dissolved in distilled water and diluted to $1 \mathrm{~L}$. 
- $2 \%$ citric acid monohydrate solution $\left(\mathrm{H}_{3} \mathrm{C}_{6} \mathrm{H}_{5} \mathrm{O}_{7} \cdot \mathrm{H}_{2} \mathrm{O}\right): 20 \mathrm{~g}$ of citric acid was diluted to $1 \mathrm{~L}$ with distilled water.

- $0.1 \mathrm{M}$ hydroxylamine-hydrochloride $\left(\mathrm{NH}_{2} \mathrm{OH} . \mathrm{HCl}\right)$ in $0.01 \mathrm{~N}$ nitric acid: $6.95 \mathrm{~g}$ $\left(\mathrm{NH}_{2} \mathrm{OH} \cdot \mathrm{HCl}\right)$ was dissolved and diluted to $1 \mathrm{~L}$ with $0.01 \mathrm{~N} \mathrm{HNO}_{3}$. The $0.01 \mathrm{~N}$ nitric acid was prepared by diluting $3 \mathrm{~mL}$ concentrated nitric acid to $5 \mathrm{~L}$ with distilled water.

The procedure for each extraction was the same except for the extractant used. The soils extracted were ones that had been sieved and consisted of particles $<2 \mathrm{~mm}$ in size. Those samples were: SP2-2-ABC, SP2-3-ABC, SP4-1A/2A, SP5-1-AB, SP8-1A/2A/3A, and SP9-1A/3A. Forty milliliters of the extractant were added to $5 \mathrm{~g}$ of each soil (1:8 soil/solution ratio) and mixed for $2 \mathrm{~h}$ in a shaker. The samples were then centrifuged for $6 \mathrm{~min}$ at about $3000 \mathrm{rpm}$ in an IEC HN-SII centrifuge. The liquid was decanted and filtered through a $0.45-\mu \mathrm{m}, 25-\mathrm{mm}$, Acrodisc. This leachate was then submitted to the Y12 Environmental Analysis Laboratory for total uranium analysis by mass spectroscopy and trace element analysis by inductively coupled plasma atomic emission spectroscopy (ICPAES). In addition to the leachates, some unleached soil was also submitted for analysis so that the percent of uranium and trace metals extracted could be calculated.

One additional extraction was conducted employing the citrate-bicarbonate-dithionite (CBD) method. This method is summarized as follows.

- Sodium citrate-bicarbonate-dithionite (CBD) method: $0.3 \mathrm{M}$ sodium citrate $(88 \mathrm{~g}$ tribasic sodium citrate, $\mathrm{Na}_{3} \mathrm{C}_{6} \mathrm{H}_{5} \mathrm{O}_{7} \cdot 2 \mathrm{H}_{2} \mathrm{O}$, per liter); $1 M$ sodium bicarbonate $(84 \mathrm{~g}$ $\mathrm{NaHCO}_{3}$ per liter); and $5 \mathrm{~g}$ sodium dithionite, $\mathrm{Na}_{2} \mathrm{~S}_{2} \mathrm{O}_{4}$.

For the CBD extraction, $800 \mathrm{~mL}$ of sodium citrate were mixed with $100 \mathrm{~mL}$ sodium bicarbonate for an 8:1 citrate/bicarbonate solution. Sixty mililiters of this solution were added to $15 \mathrm{~g}$ of soil in a $200-\mathrm{mL}$ centrifuge bottle. The soil plus citrate/bicarbonate solution was then heated in a water bath to $75-80^{\circ} \mathrm{C}$. At about $78^{\circ} \mathrm{C}, 5 \mathrm{~g}$ of sodium dithionite were added and the mixture stirred for $15 \mathrm{~min}$. After digestion, the mixture was centrifuged, the solution decanted, and filtered through a $0.45-\mu, 25-\mathrm{mm}$, Acrodisc. This 
leachate was also submitted to the Y-12 Environmental Analysis Laboratory for total uranium by mass spectroscopy and trace element analysis by inductively coupled plasma atomic emission spectroscopy (ICP-AES).

The CBD treatment soil samples were separated into sand-, silt-, and clay-sized fractions by the wet sieving and centrifugation methods for mineralogical analysis by $\mathrm{x}$-ray powder diffraction (XRD) and heavy liquid density separation. Clay fractions were saturated with magnesium and potassium and excess salts were removed by washing. Oriented clay specimen slides, two for magnesium-saturated clay and three for potassiumsaturated clay were prepared using the filter membrane peel technique (Drever 1973). One of the magnesium-saturated clay slides was solvated with ethylene glycol and the second and third sets of potassium-saturated clay slides were heated at 300 and $550^{\circ} \mathrm{C}$. XRD scans began and ended at 2 and 30 degrees, two theta, respectively, using copper $\mathrm{K}$ alpha radiation on a Norelco-Philips x-ray diffractometer.

The dry, undisturbed, surface soil samples collected in plastic dishes and soil clumps from the subsurface were embedded in epoxy resin under a vacuum allowing the solution to move into soil micropores. After resin polymerization, microscopic specimens about $2 \times 3.5 \mathrm{~cm}$ ), were prepared by cutting the soil resin blocks perpendicular to the soil surface by a diamond saw. The specimens were polished with silicon carbide powder. Scanning electron microscopy (SEM), utilizing both secondary electron imaging (SEI) and backscattered electron imaging (BEI) in conjunction with energy dispersive $\mathrm{X}$-ray analysis (EDX), was used for analysis of morphology, particle size, and elemental distributions (Lee 1990).

Lithium metatungstate solution with density $2.8 \mathrm{~g} / \mathrm{mL}$ was used for the heavy liquid density separation. About $10 \mathrm{~mL}$ of the lithium metatungstate solution was transferred into a $20-\mathrm{mL}$ plastic centrifuge tube and to about $3 \mathrm{~g}$ of sand fractions separated after $\mathrm{CBD}$ treatment to the solution. After mixing for $5 \mathrm{~min}$ and centrifugation for $10 \mathrm{~min}$ $(2000 \mathrm{rpm})$, the bottom of the tube containing heavy particles was placed in liquid nitrogen to freeze the bottom, thus allowing the upper (floating) part to be poured off to separate the fractions. Both the heavy and floating fractions were collected on filter 
papers $(0.45 \mu \mathrm{m})$ and washed with distilled water using a vacuum filtering apparatus. The fractions were placed in petri dishes, and uranium concentrations were determined by gamma spectroscopy as described above. A portion of the floating and heavy fractions was embedded in epoxy resin solution for SEM, EDX, and XRD analyses (in progress). These analyses would provide information related to elemental composition and crystalline phase of uranium containing particles.

\section{RESULTS AND DISCUSSION}

\section{Soil Description and Gamma Spectroscopic Analysis}

Reference Soils: Undisturbed soils on and around the Fernald Site are classified as either Fincastle or Henshaw series. The Henshaw series consists of deep, somewhat poorly drained, moderately permeable soils that formed in alluvium from calcareous loess (SCS 1982). Henshaw soils would be on a stream terrace as seen from the southeast portion of the Fernald Site. The Fincastle series consists of deep, somewhat poorly drained soils that formed in loess and in the underlying loam till. Permeability of Fincastle soils is moderate in the upper solum and moderately slow in the underlying glacial till. Current usage of the lands is farming. The results of gamma spectroscopic analysis are in Table 2. Uranium contents of the background soils were very close to the lower detection limit of the gamma spectroscopic analysis. Both mass and alpha spectroscopies were performed for reference soil uranium analysis.

Plant 2/3 Area: The area surrounding Plant $2 / 3$ has been highly disturbed from past construction and decontamination activities. Limestone gravels were on the surface and mixed into the soil as deep as $30 \mathrm{in}$. from the surface. Two soil core samples, SP1 and SP2, were taken from the area (Fig. 1). Both core samples had a very high gravel content, and bulk density of the soils ranged from 1.2 to $1.9 \mathrm{~g} / \mathrm{cm}^{3}$ depending on the clay and moisture contents of particular core segments. Soil ranged from light yellowish brown (10YR 4/2) to yellowish gray (2.5YR 5/0). The SP1 core had a clay layer at the bottom $(18+$ in.) and had a very low uranium content (Table 3). The SP2 core was selected for the characterization study because the soil was contaminated uniformly down to 32 in. 


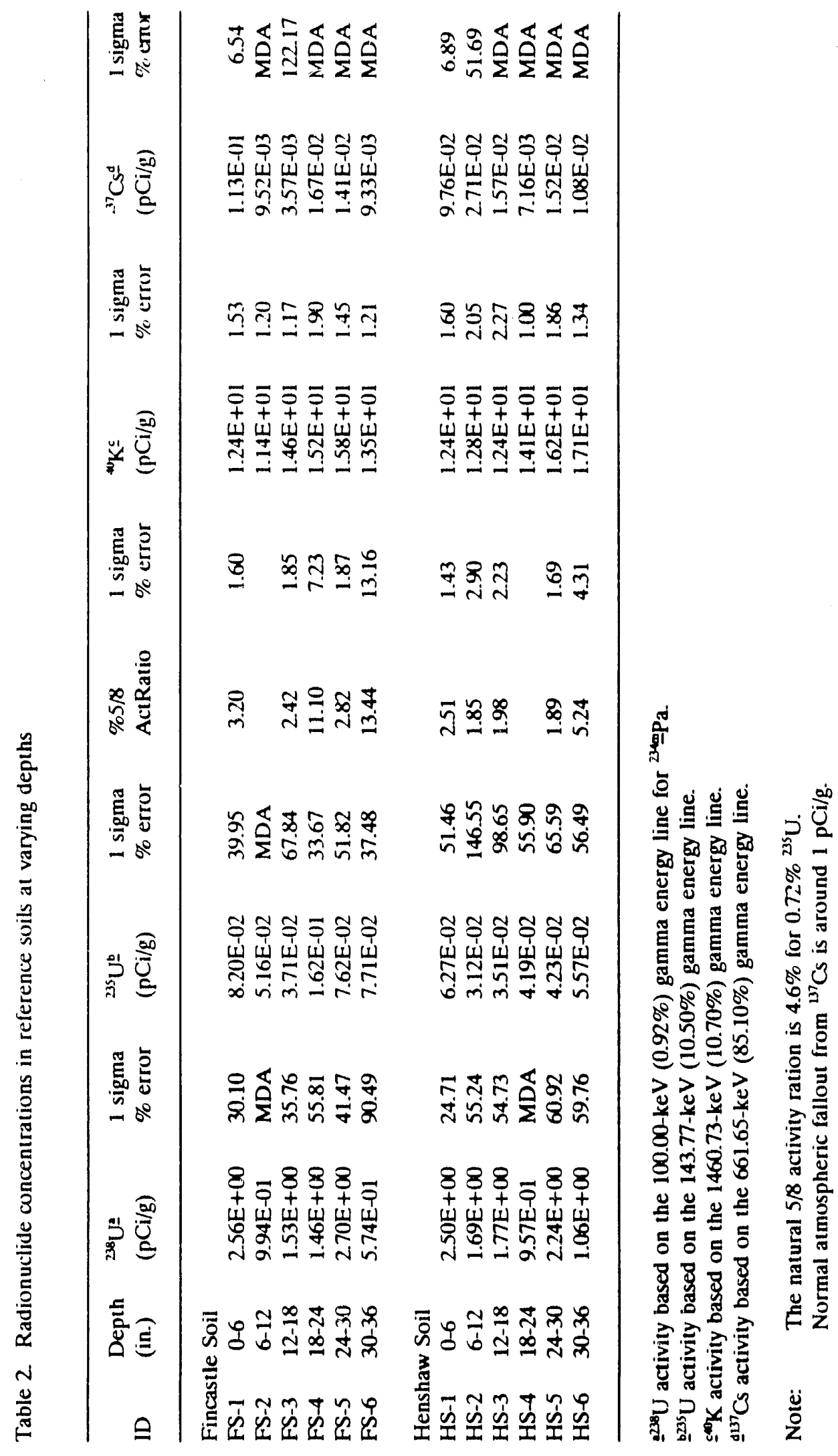




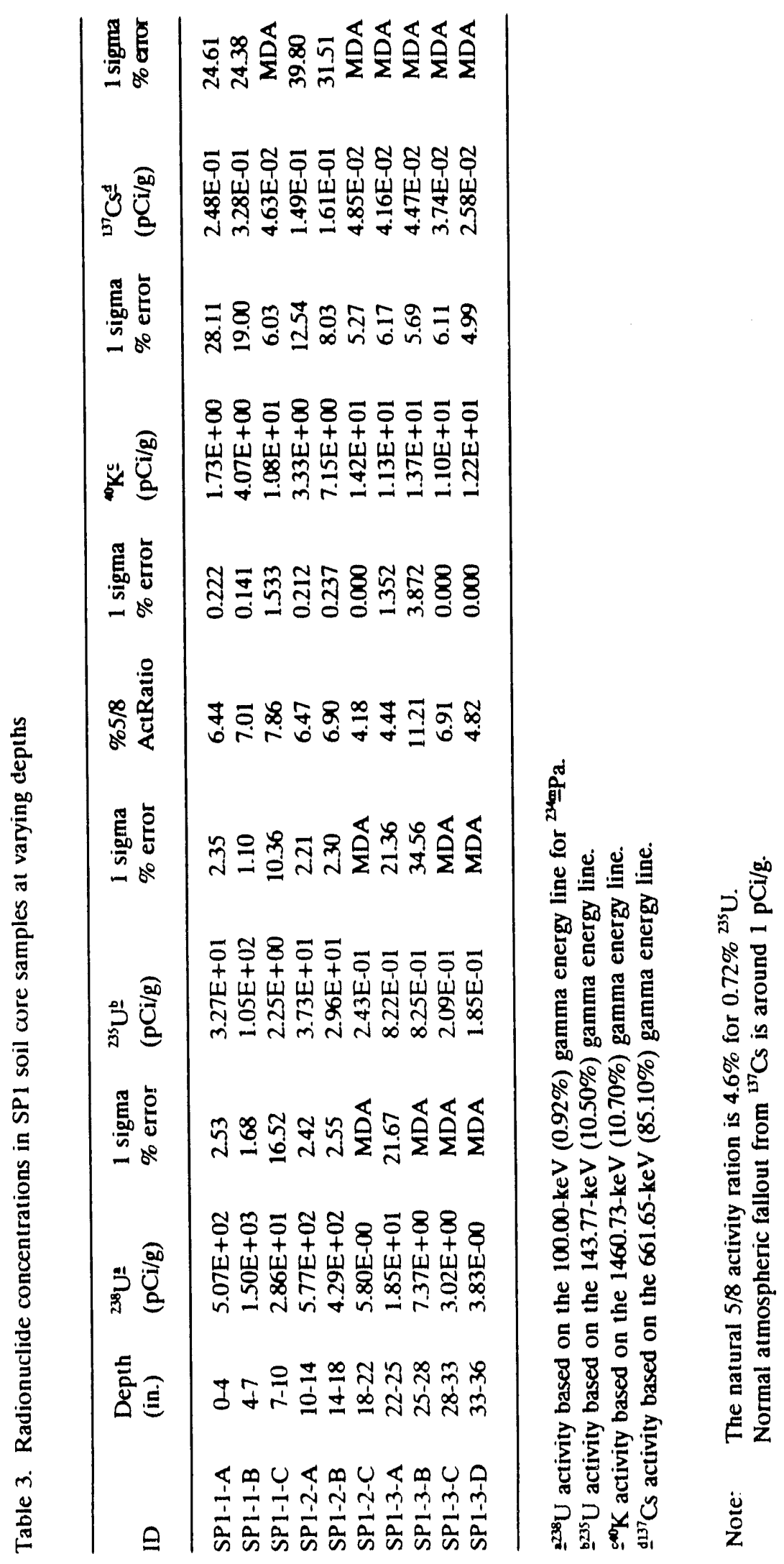


Table 4 gives the activities of individual segments. In order to examine uniformity of contamination characteristics, two soil samples were chosen at the different depths from the SP2 core. The SP2-2 and SP2-3 samples were prepared by combining A, B, and C segments of the core sections from 10 to $20 \mathrm{in.}$ and 20 to $31 \mathrm{in.}$ depth, respectively.

Plant 1 Drum Storage Area: This area is located in the northwestern part of the plant, and the underlaying soils should be Fincastle series if they have not been too deeply disturbed. Soil sampling sites are located on the west side of the Drum Storage Area. The soil sampling area was covered by fescue grass. Most of the area was mowed but the northern portion of the grass area was left alone because the area was designated as a regulated zone. The SP3 core was taken near the concrete pad in the south and the SP4 core was taken from the unmowed area in the north (Fig. 1). The unmowed area was a surface water receiving area from the Drum Storage Pad. Soil in the SP3 core had a light yellowish brown (10YR 6/4) to brown (10YR 5/3) color with weakly developed soil structure and about 30 to $60 \%$ limestone gravels. The presence of the angular limestone gravel indicated that the SP3 core area had been highly disturbed from past activities. The gamma spectroscopy results of the core indicated that the level of uranium contamination (Tables 5 and 6) was $<100 \mathrm{pCi} / \mathrm{g}$ in the upper 4 in. and $<10 \mathrm{pCi} / \mathrm{g}$ below 7 in. Soil in the upper part of the SP4 core had a light to dark brown color with a lower dark gray $(2.5 \mathrm{Y} 4 / 0)$ clay reducing zone. Gravel content in the soil core was less than $8 \%$. The soil had relatively abundant plant roots, loam texture in the surface horizon (Ap), and clay loam textured subsurface horizons. Depth of considerable contamination ( $91 \mathrm{pCi} / \mathrm{g}$ ) was above 7 in. The SP3 core was selected for the Phase I investigation because of the high contamination level of the soil core.

Decontamination ParidDrum Baling Area: This area is located in the northeast corner of the site and is used as a storage area for contaminated materials (Fig. 1). Two soil core samples were taken from the area. The SP5 core was taken from the area where the surface was covered by gravel-sized contaminated slag materials. The field survey indicated that the slag materials were the major source of the radioactivity in the area. Smaller-sized slag material was mixed into soil down to $9 \mathrm{in}$. of the core and soil had pale brown to yellowish brown color and silt loam to clay loam texture. Considerable 


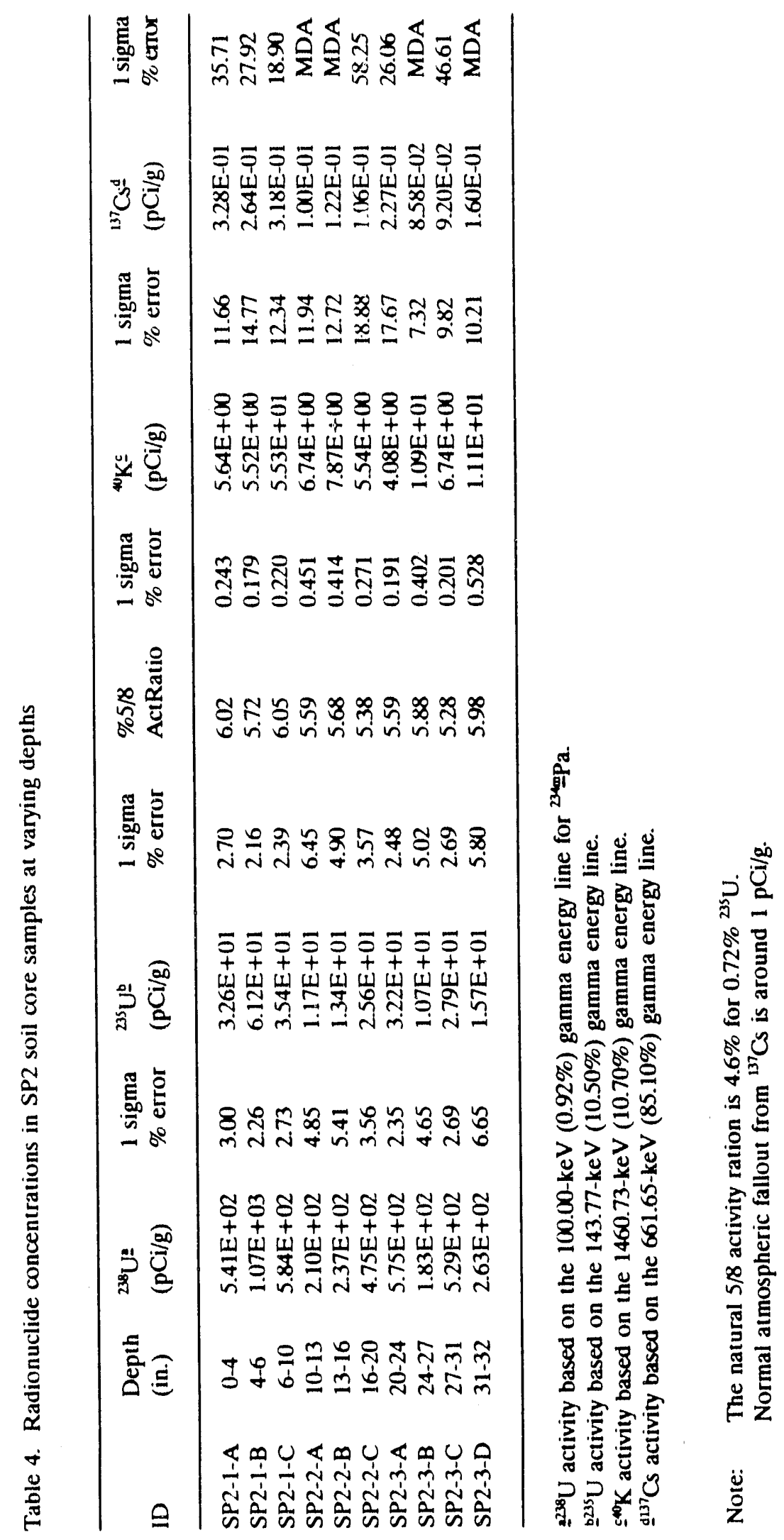




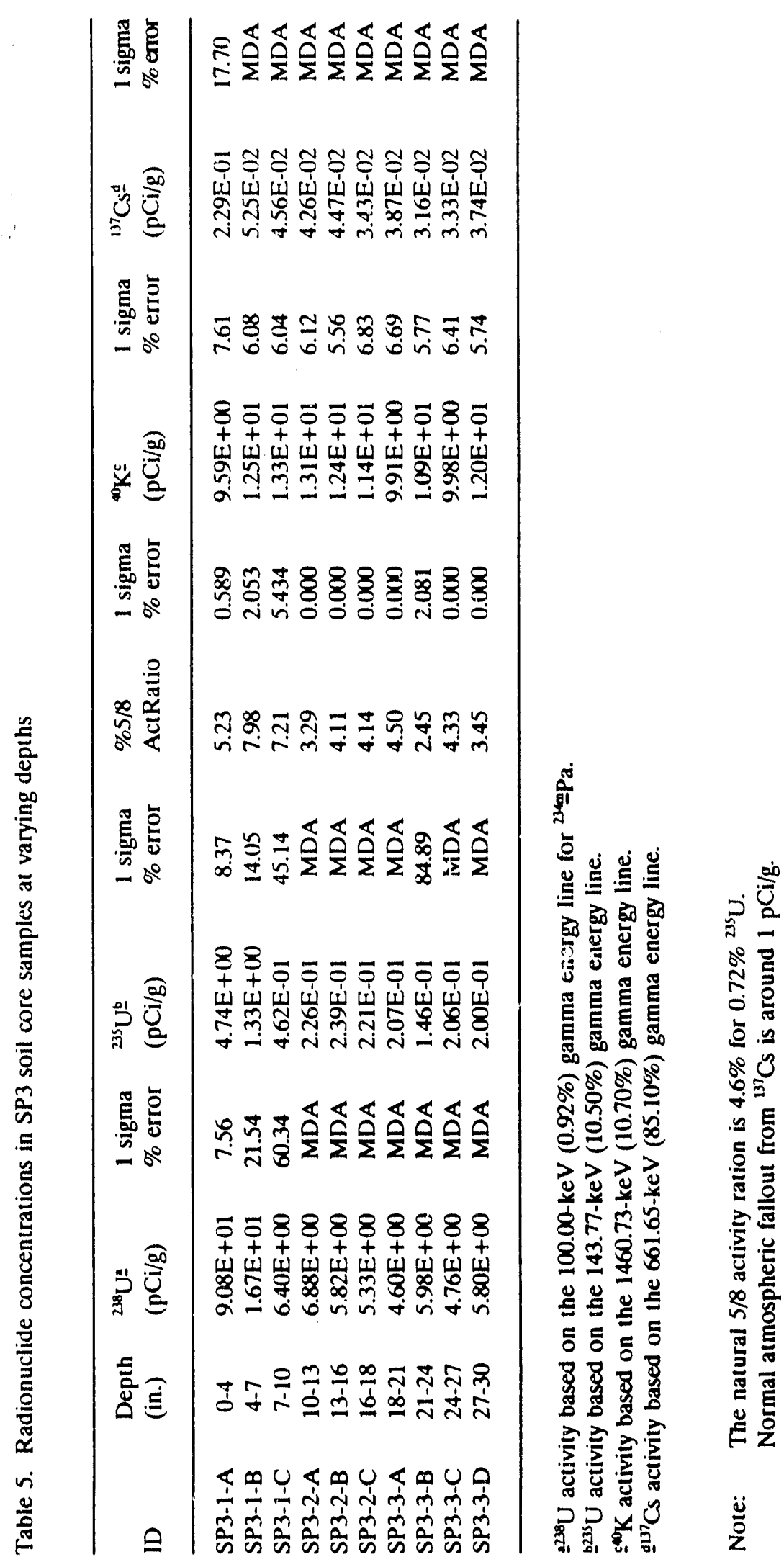




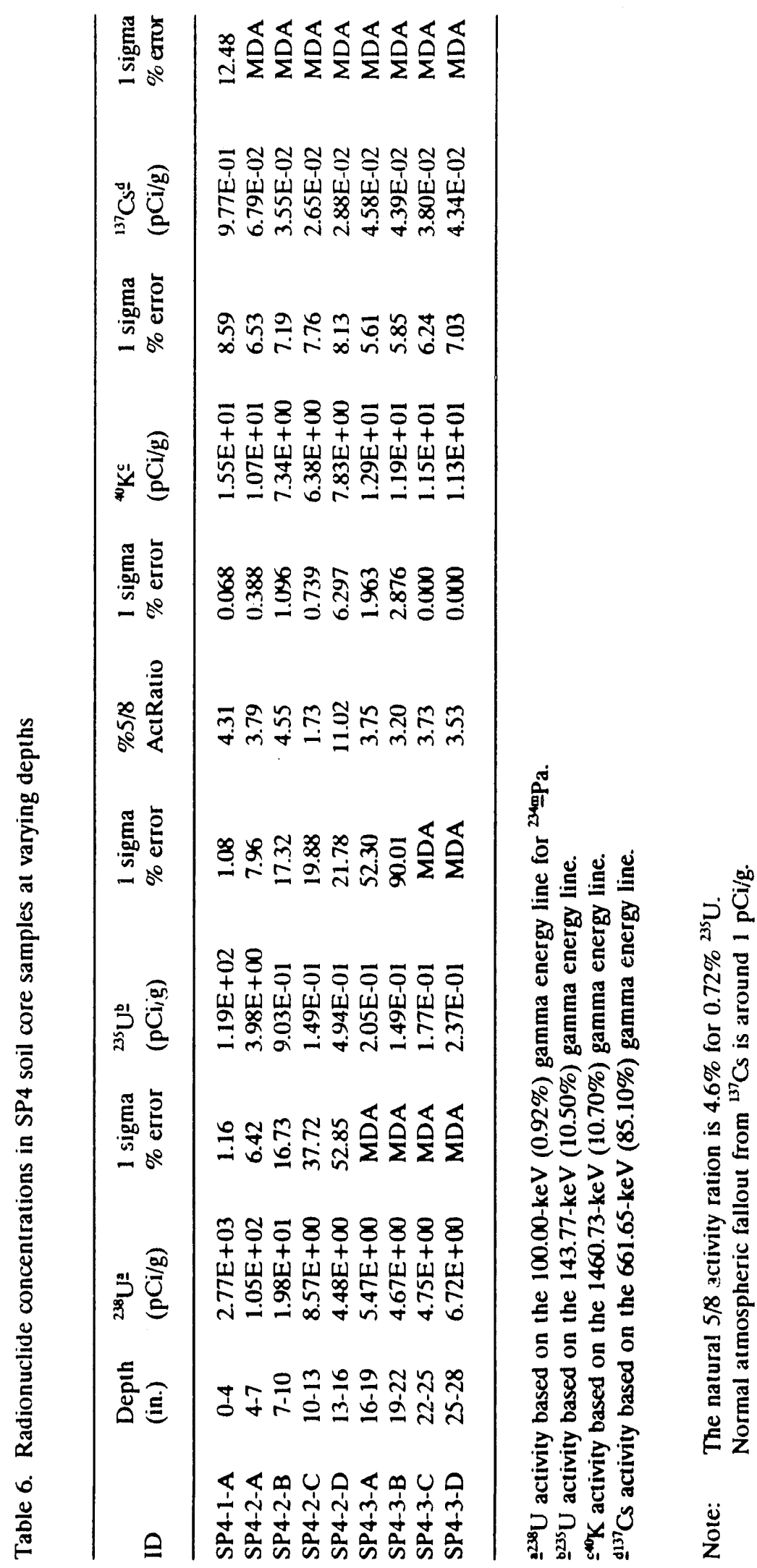


radioactivity was detected from the top 8 in. of the core. The SP6 core was taken near the railroad track and east of the Decontamination Pad (Fig. 1). The soil had yellowish brown color with clay loam texture and contained limestone fragments throughout the soil core. Gamma spectroscopy showed that uranium contamination of the SP6 soil core was relatively lower than the SP5 soil core (Tables 7 and 8 ). Therefore, the 0 - to 9-in. segment of the SP5 soil core was chosen for characterization.

Plant 6 Area: The initial sampling plan was to collect samples from the northeast side of Plant 6. An alternate area was selected because the proposed area was disturbed by construction activities. The SP7 and SP8 core sampling sites were located further north of the initially planned area (Fig. 1). The SP7 site was considerably contaminated by waste spills or dumping activities in the area (Table 9). However, the area selected for SP8 soil core was relatively undisturbed. The area was selected to obtain a soil sample which had been contaminated by airborne uranium waste. Therefore, the SP8 soil core was investigated in this phase of characterization. The SP8 soil had light brown color, well developed soil horizons, silt loam texture, and high organic matter content contributed by growing grass in the area for considerable time. The uranium contamination was limited to only a few inches below the surface (Table 10). Therefore, a composite soil sample was prepared by combining the top 3 in. from three soil cores.

Incinerator Area: The surface soil was contaminated by the past incinerating activities of the old primitive incinerator located in the area. The contaminated area was covered by fescue grass and three 12-in. cores per site were obtained from near the curb of the asphalt-paved driveway (Fig. 2). The SP9 sampling site was relatively closer to the old incinerator than the SP10 sampling site. Field survey results indicated that the level of surface soil contamination decreased with increasing distance from the incinerator (Tables 11 and 12). The soil core samples had a well developed Ap horizon with dark grayish brown color, fine granular structure, but had small limestone gravels throughout the cores. The top 3-in. segments of the SP9 cores were used for this investigation. 


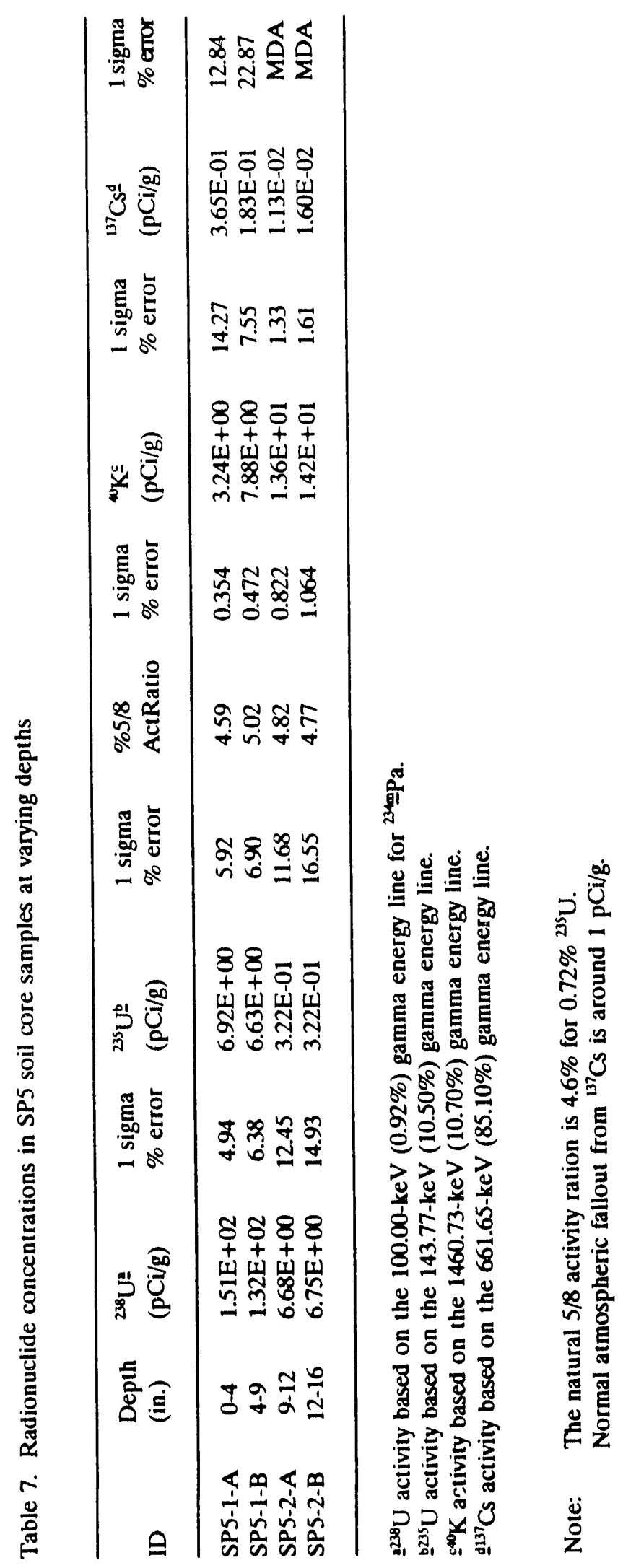




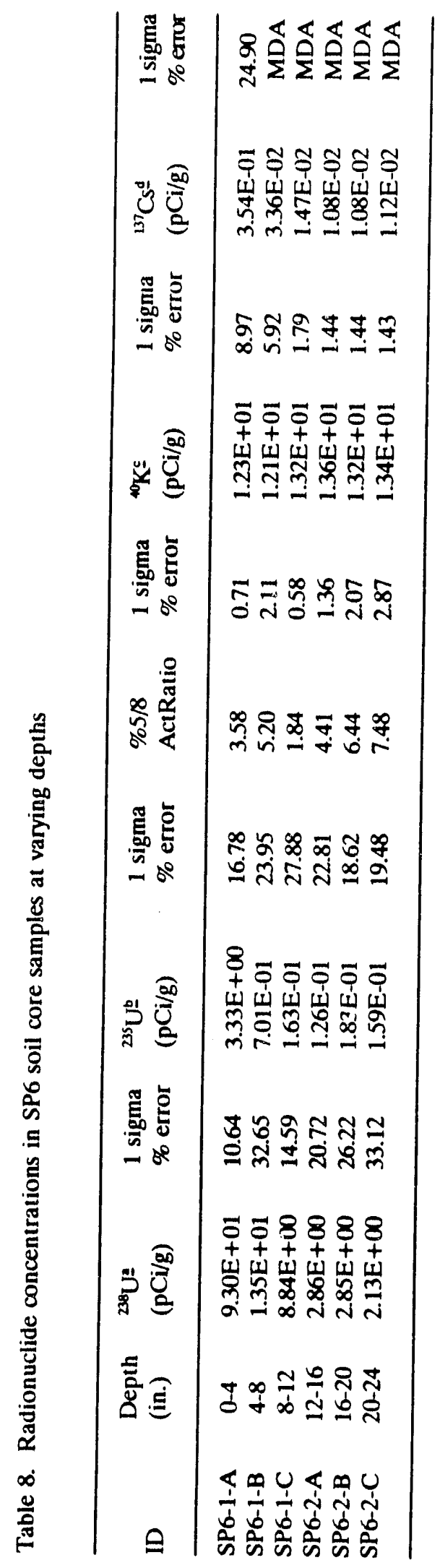

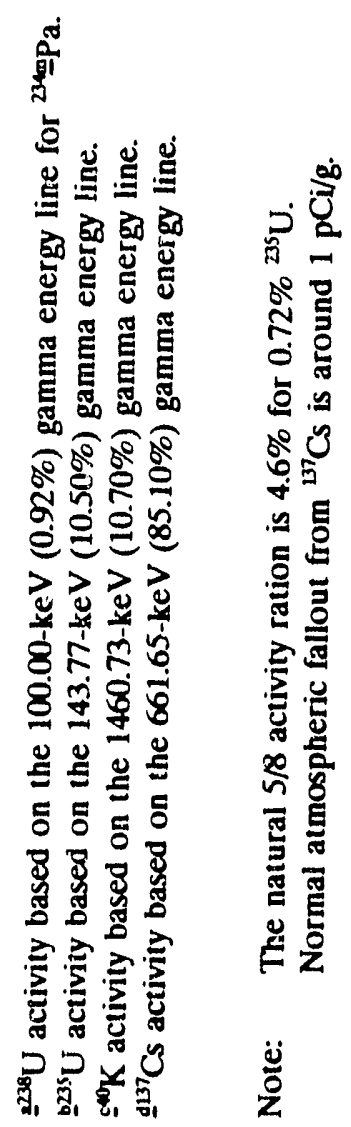




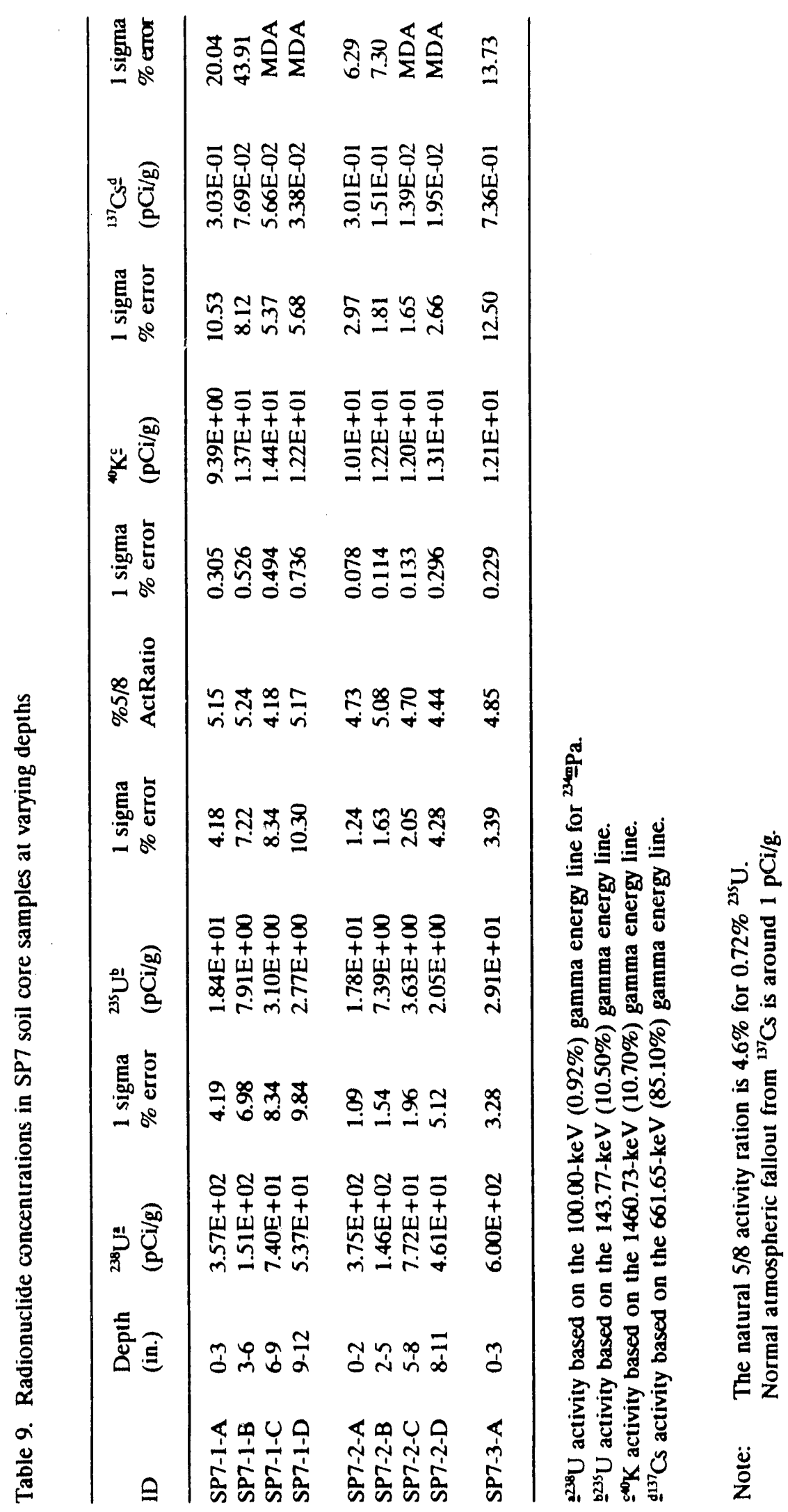




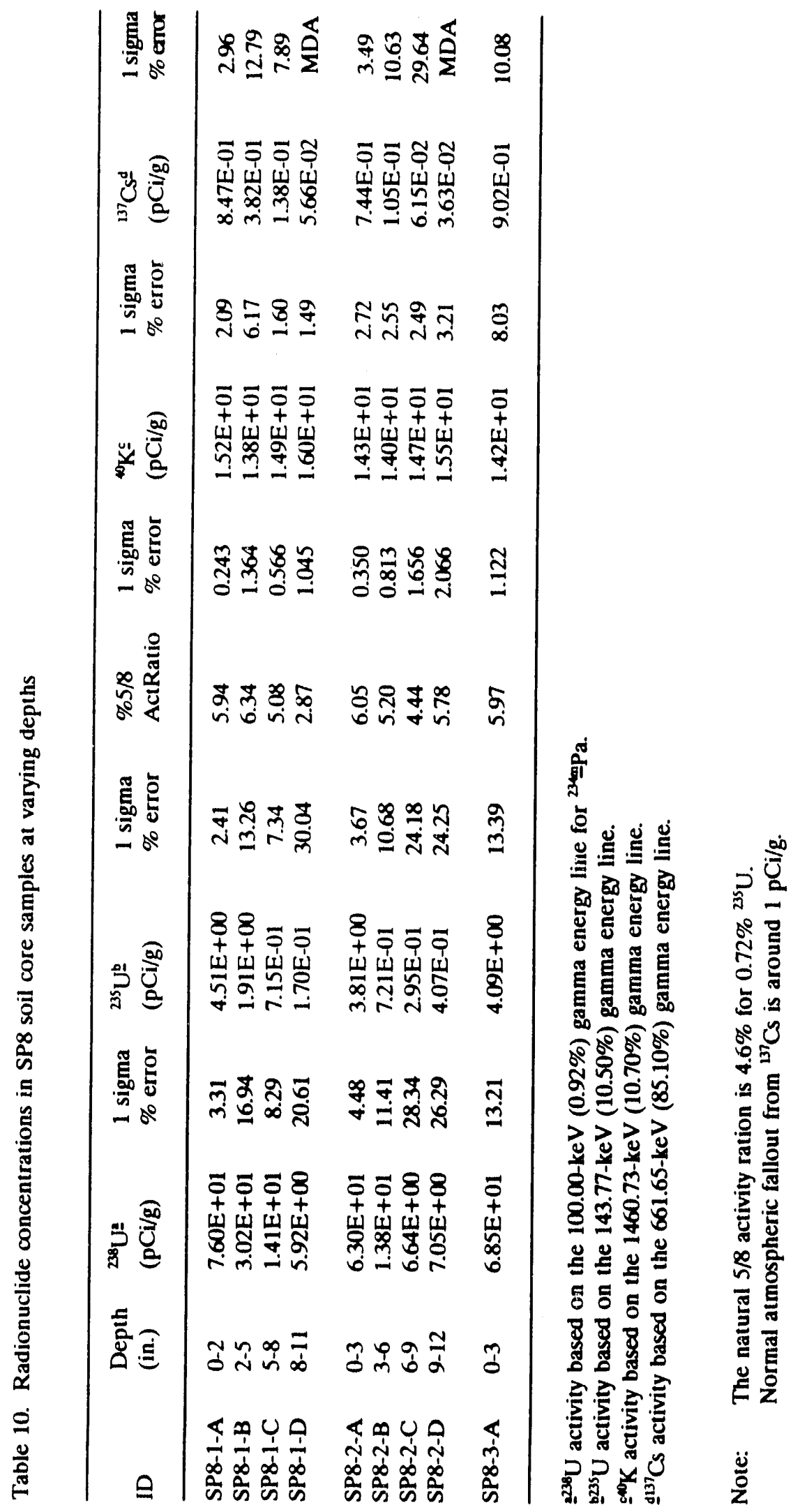




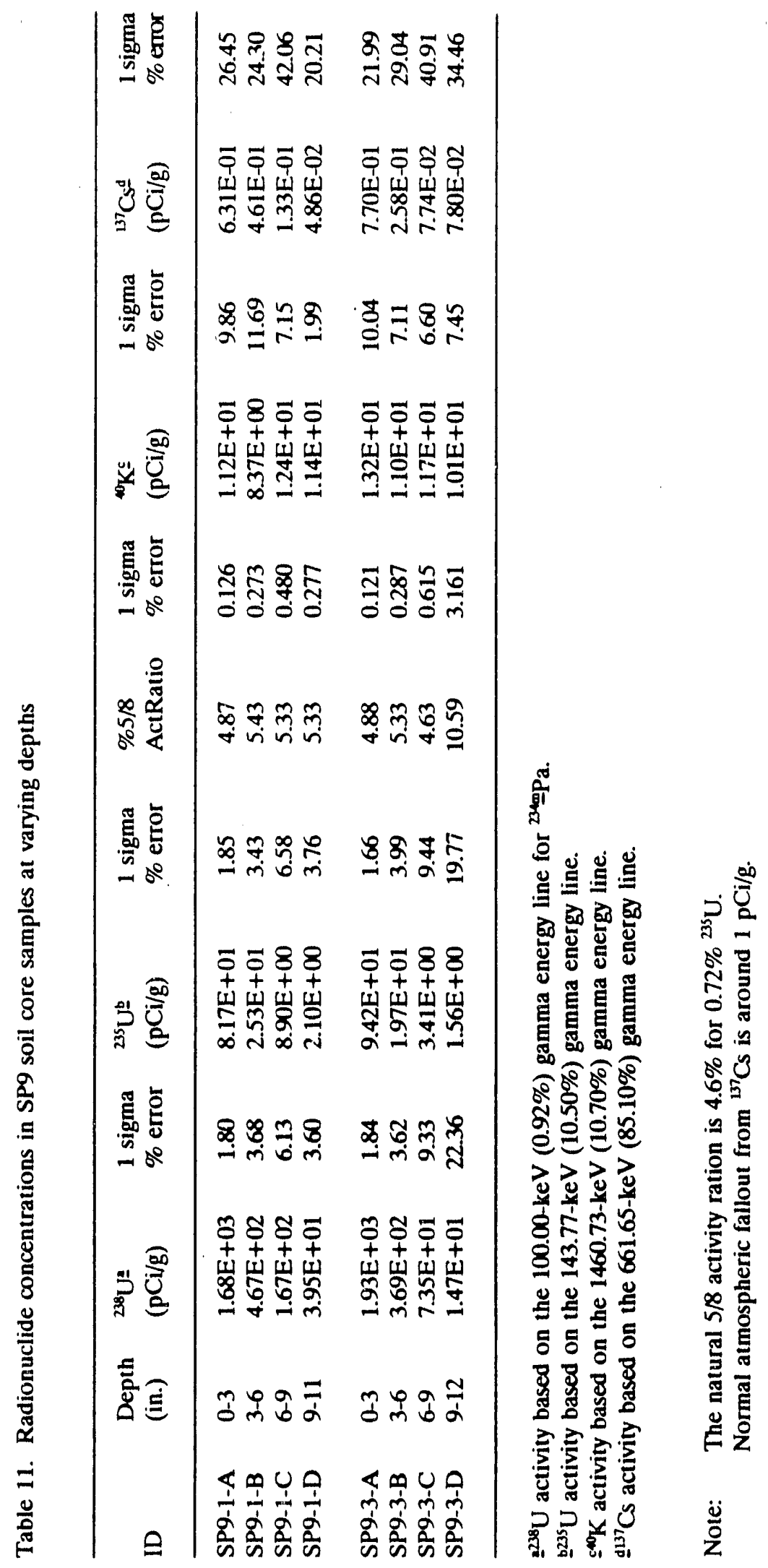




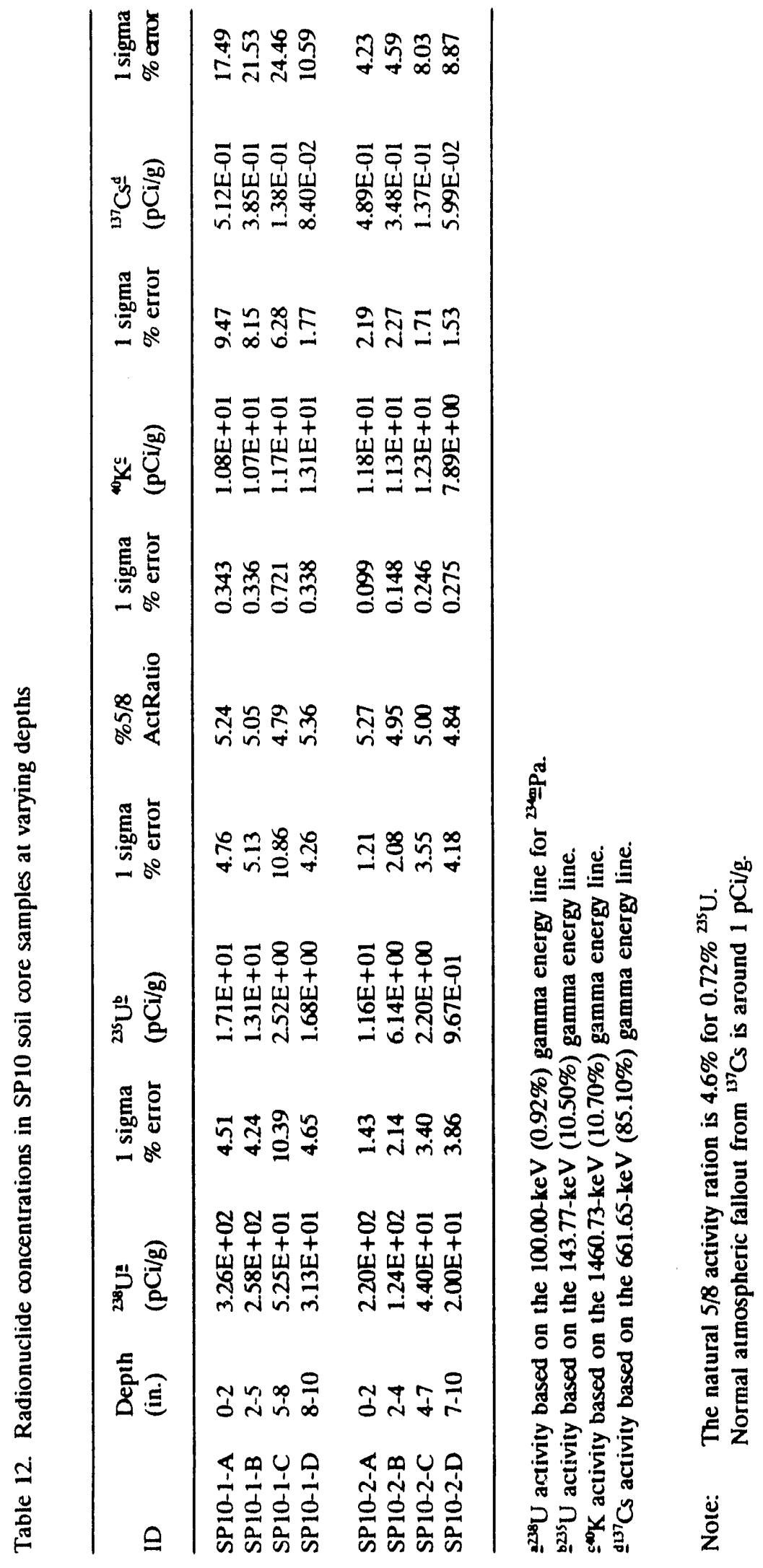




\section{Soil Particle Size Distributions}

The results of the particle size fractionation are in Table 13 . The $>2-\mathrm{mm}$ gravel fractions were probably overestimated because of surface coating of finer materials on coarse fragments. 'The SP2-2 and SP2-3 samples had a similar particle size distribution pattern. Gravel fractions constituted about 56 to $59 \%$ by weight and other fractions were less than $20 \%$. The SP4 sample had $8 \%$ gravel, $20 \%$ sand, $54 \%$ silt, and $18 \%$ clay that, if the gravel fraction is discounted, is similar to the surface texture of local loess soils (see reference soils). The SP5-1 sample had 54\% gravel, $15 \%$ sand, $25 \%$ silt, and $16 \%$ clay, with the high gravel content reflecting the presence of the coarse slag materials in the soil surface layer. The surface soil of the SP8 sample had 34\% sand, $47 \%$ silt, and $19 \%$ clay. This soil had a similar texture as the reference soils, indicating that the sampling area had been minimally disturbed (Table 13). The surface soil of the SP9 cores had $13 \%$ gravel, $21 \%$ sand, $53 \%$ silt, and $13 \%$ clay. The mixing with limestone gravel altered the soil texture somewhat, but the texture of the SP9 soil was similar to other less disturbed soils inside the plant.

The results of the particle size distribution suggest that (1) soils inside the plant boundary were highly disturbed from past construction activities; (2) most of the coarse fragments ( $>2 \mathrm{~mm}$ ) were limestone that was used as fill, cover, and road construction materials; (3) the presence of limestone fragment is reflected in the relatively high $\mathrm{pH}$ of the surface soils in the sampling areas (Table 14); and (4) the weak alkaline pH and carbonate mineral availability would contribute to a high uranium concentration in perched water zones in the soils. The amounts of uranium, cation, and anions dissolved during size separation were given in Table 15.

\section{Uranium Distribution with Particle Size in Soils}

Analytical results of uranium in the soils (Table 13) were expressed in concentration of each fraction $(\mu \mathrm{g} / \mathrm{g})$ as well as contribution of each fraction to total soil concentration (\%). 


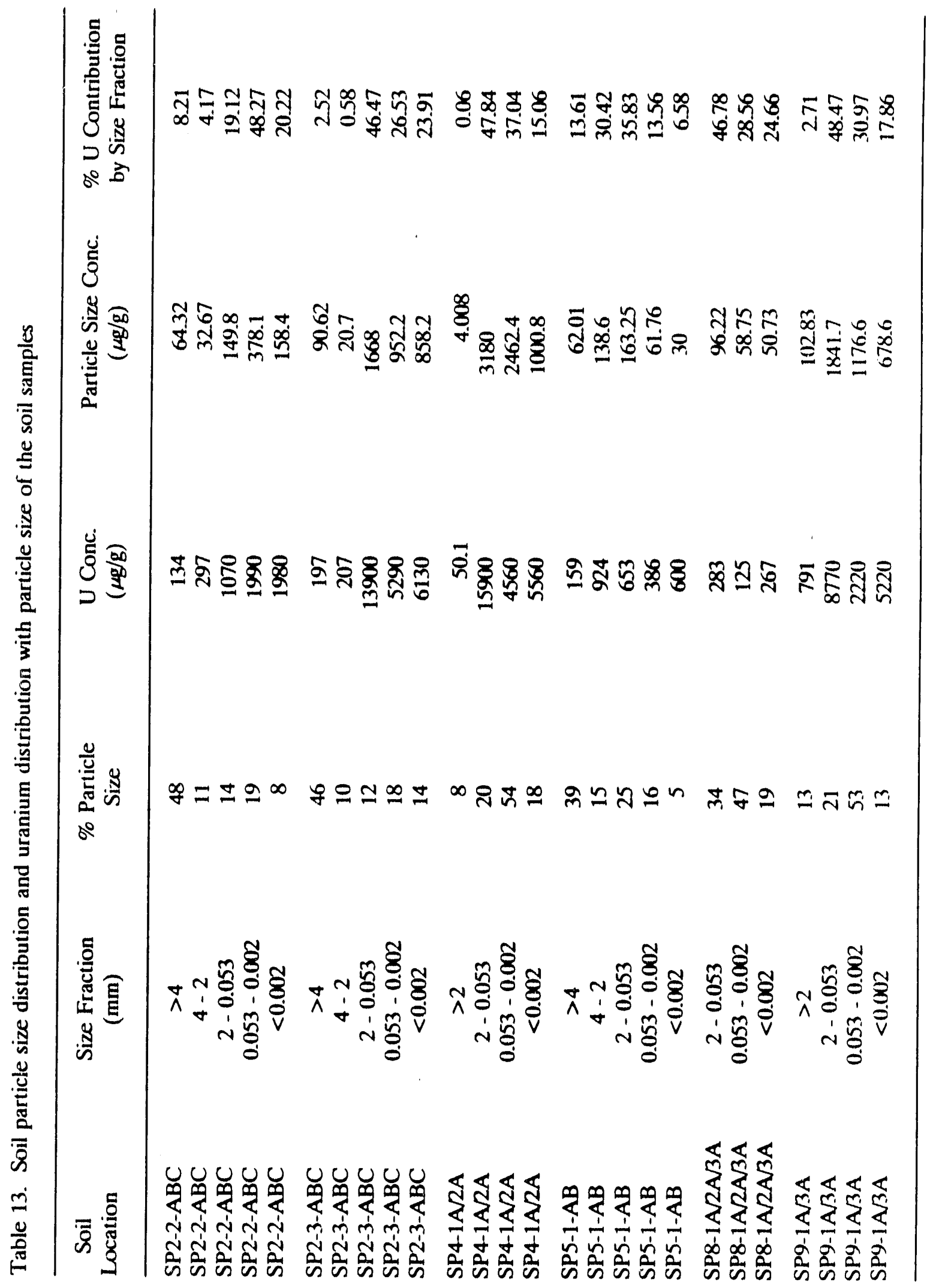


Table 14. pH measurements of contaminated and reference soils

\begin{tabular}{|c|c|c|c|}
\hline Sample Name & $\mathrm{pH}$ & Sample Name & $\mathrm{pH}$ \\
\hline SP1-1-A & 8.2 & SP6-1-A & 8.2 \\
\hline SP1-1-B & 8.3 & SP6-1-B & 8.6 \\
\hline SP1-1-C & 8.1 & SP6-1-C & 8.3 \\
\hline SP1-3-A & 8.2 & SP6-2-A & 8.4 \\
\hline SP1-3-B & 8.1 & SP6-2-B & 8.2 \\
\hline SP 1-3-C & 7.8 & SP6-2-C & 8.4 \\
\hline SP2-1-A & 7.8 & SP7-1-A & 8.2 \\
\hline SP2-2-A & 8.1 & SP7-1-B & 8.2 \\
\hline \multirow[t]{2}{*}{ SP $2-3-A$} & 8.0 & SP7-1-C & 8.2 \\
\hline & & SP7-1-D & 8.2 \\
\hline SP3-1-A & 8.3 & SP8-1-A & 6.1 \\
\hline SP3-1-B & 8.4 & SP8-1-B & 6.9 \\
\hline SP3-2-A & 8.1 & SP8-1-C & 7.3 \\
\hline SP3-2-B & 8.4 & SP8-1-D & 7.6 \\
\hline SP3-2-C & 8.5 & & \\
\hline SP3-2-D & 8.3 & SP9-1-A & 7.2 \\
\hline SP3-3-A & 8.2 & SP9-3-B & 7.8 \\
\hline SP3-3-B & 8.1 & SP9-3-C & 8.0 \\
\hline SP3-3-C & 8.1 & SP9-3-D & 8.2 \\
\hline SP3-3-D & 8.0 & & \\
\hline SP4-1-A & 7.9 & SP10-1-A & 7.3 \\
\hline SP4-2-A & 8.3 & SP10-1-B & 7.6 \\
\hline SP4-2-B & 8.4 & SP10-1-C & 8.0 \\
\hline SP4-2-C & 8.5 & SP10-1-D & 8.3 \\
\hline SP4-2-D & 8.2 & & \\
\hline SP4-3-A & 8.2 & Henshaw & 6.3 \\
\hline SP4-3-B & 8.2 & Fincastle & 5.4 \\
\hline SP4-3-C & 8.3 & & \\
\hline SP4-3-D & 7.6 & & \\
\hline SP5-1-A & 8.3 & & \\
\hline SP5-2-A & 7.9 & & \\
\hline SP 5-2-B & 7.9 & & \\
\hline
\end{tabular}




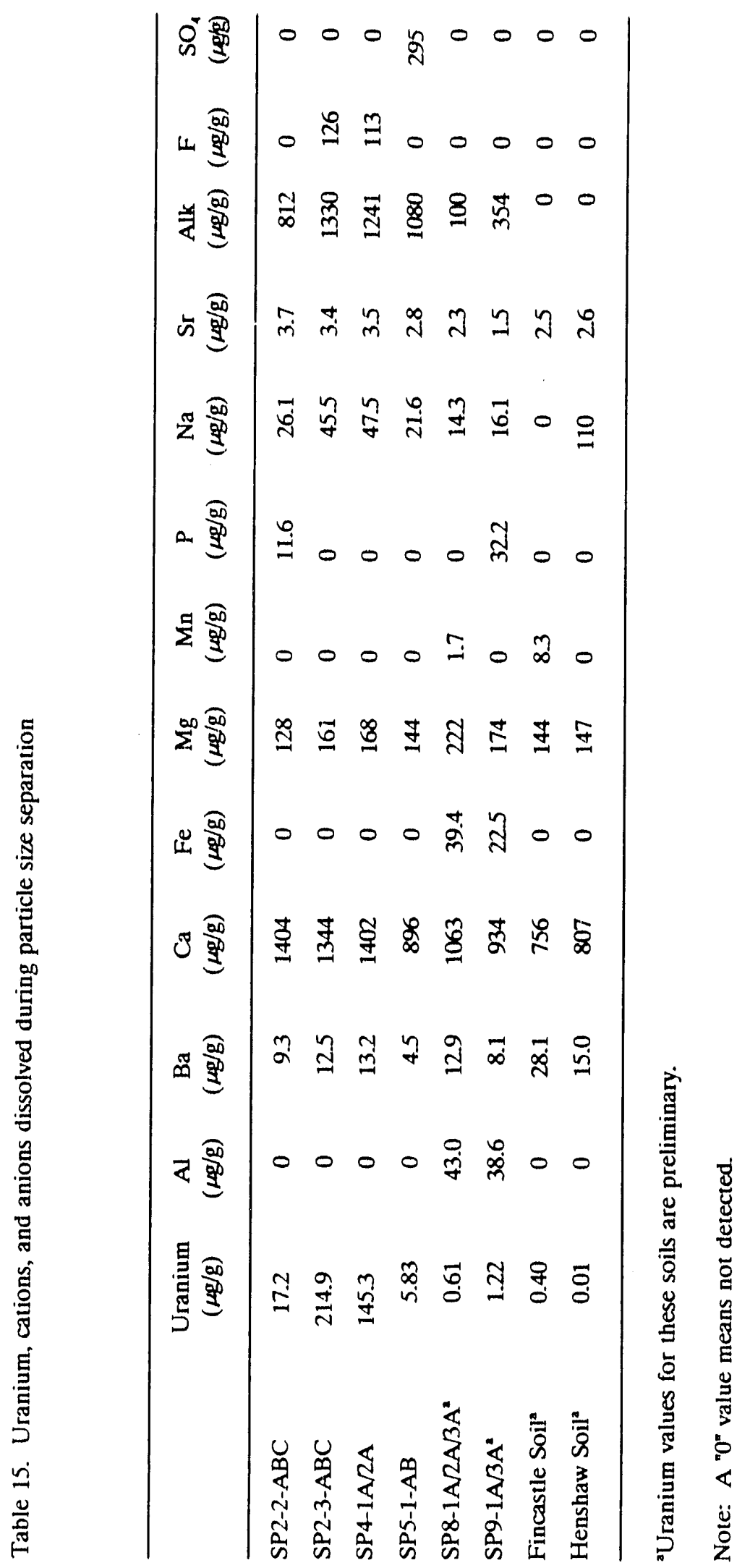


The gravel fractions (limestone fragments) of the SP2-2 and SP2-3 samples had low uranium contamination and their contribution to total uranium was less than $13 \%$. The sand fraction of SP2-2 had a moderate level of contamination and contribution to total uranium concentration, but the sand fraction of SP2-3 contributed about $46 \%$ to the total soil uranium concentration, although the soil sample had only $12 \%$ sand by weight. On the other hand, the silt fraction of SP2-2 was the largest contributor of uranium to the soil, although the sample had only $19 \%$ silt by weight. The clay fractions of the both sample had a moderate contribution (20 to $24 \%$ ).

The SP4 sample had the highest contamination among the samples $(0.665 \%)$. The uranium contribution by the gravel fraction was minimal $(0.06 \%)$. The sand fraction had the highest concentration $(15.9 \mathrm{mg} / \mathrm{g})$ as well as the highest contribution $(48 \%)$ to the total uranium in the soil. The silt and clay fraction had a considerable amount of uranium but their contributions were lower than the sand fraction (Table 13).

The uranium distribution pattern of the SP5 sample was distinctively different from other samples. The SP5 sample had a large amount of gravel fractions (54\%) and the gravel fractions were the major uranium contributor (44\%). The second largest contributor was the sand fraction (36\%). In other samples, gravel fractions were minor uranium contributors regardless of the amount of limestone gravel in the soil.

The uranium concentration of the SP8 sample was the lowest among the samples, but it was still much higher than the background level. The sand and clay fractions had a higher concentration than that of the silt fraction. The sand fraction contributed about $47 \%$ of the total uranium in the soil. The uranium distribution in the SP9 size fractions was similar to other samples such as SP4 and SP8. The sand fraction had a higher uranium concentration and was a major contributor although it was a minor size fraction of the soil.

The results of the uranium distribution with size fractions indicate that (1) the majority of uranium in the soils was as individual discrete particles or as smaller particles cemented to silt, sand, and gravel fractions rather than an adsorbed form on clay minerals; 
(2) the dominant size fraction for uranium contribution would be sand for the SP2-3, SP4, SP8, and SP9, silt for the SP2-2, and gravel for the SP5; and (3) separation and removal of a particular size range would not help a great deal for the waste volume reduction for most samples except the separation of the gravel fraction from the SP2 soil.

\section{Microscopic Analyses}

Polished sections of soil aggregates embedded in epoxy resin were examined by SEM and EDX. Most of the uranium containing clumps in the SP2 samples consisted of aggregates of fine silt or clay particles. The uranium containing aggregates were composed of silicon, aluminum, calcium, phosphorous, and iron (Plate 1 and 2). In the micrographs, individusi: uranium particles are brighter than silicate minerals. The SP4 specimen contained a wide variety of sizes and shapes of particles containing uranium (Plates 3 and 4). Some particles were composed entirely of uranium and others had iron, calcium, and/or silicon.

The slag material in the SP5 samples was the major source of uranium. Uranium occurred as a coating on the slag surface or as an occluded form in the calcium silicate matrix (Plates 5, 6, and 7). Silicon and calcium were the major elemental components in the slag matrix (Plate 5). The presence of occluded uranium in the slag would cause problems for the development of a decontamination strategy. The uranium-rich particles were much less abundant in the SP8 specimen. Most of the uranium particles were aggregated with silicate minerals. Phosphorous was commonly associated with the uranium particles (Plate 8). Numerous uranium particles having different morphology and composition were observed from the SP9 specimen (Plates 9, 10, and 11). Calcium and phosphorous were detected in some of the particles. Other particles had only uranium (possibly uranium oxides). Some of the particles were mixed with silicate particles as an aggregate form and others were a form of grain separated from a silicate matrix. 


\section{Heavy Liquid Separation}

The soil samples $(<2 \mathrm{~mm})$ were treated with CBD solution to remove amorphous iron coatings. The CBD treatment removed some of the uranium associated with coatings and precipitated/adsorbed on the surface of soil particles (see Chemical Leaching Experiment section). The removal of iron coatings and disaggregation of soil clays would assist in evaluating the effectiveness of heavy liquid separation and mineralogical analysis of the soils. The results of the heavy liquid separation are given in Table 16.

Table 16. Weight and uranium distribution of sand-size fractions after heavy liquid density separation in lithium metatungstate solution with a density $2.8 \mathrm{~g} / \mathrm{mL}$.

\begin{tabular}{llcc}
\hline Sample & Fraction & $\begin{array}{c}\text { Weight Distribution } \\
(\%)\end{array}$ & $\begin{array}{c}\text { Uranium Distribution } \\
(\%)\end{array}$ \\
\hline SP2-2-ABC & Floating & 83 & 49 \\
& Heavy & 17 & 51 \\
SP2-3-ABC & Floating & 79 & 64 \\
& Heavy & 21 & 36 \\
SP4-1A/2A & Floating & 63 & 30 \\
& Heavy & 37 & 70 \\
SP9-1A/3A & Floating & 82 & 49 \\
& Heavy & 18 & 51 \\
& & & \\
\hline
\end{tabular}

The data presented in the table were the first separation test results for the sand-sized fraction in the lithium metatungstate solution at density $2.8 \mathrm{~g} / \mathrm{mL}$. The separation 
procedure such as solid to liquid ratio, tube size, and liquid density will be modified for future experiments. The weight percent of heavy (sink) fractions varied from 17 to $37 \%$ and the percent of contribution by the heavy fraction to total concentration varied from 36 to $70 \%$. The results indicated that the heavy liquid density separation is a relatively effective method for the removal of uranium containing particles from the soils. However, the method may not be practical for massive amounts of soils in an engineering scale. Therefore, a new separation technology based on the difference of particle density should be developed for this ID program. Readjustment of the procedure after microscopic and $\mathrm{X}$-ray diffraction examination of the heavy fraction would improve the separation. The heavy liquid separation will be continued for silt and clay fractions and the results will be reported in the final report of this Phase 1 Characterization project.

\section{Mineralogical Analyses}

For mineralogical analysis, clay fractions of the soil samples were separated from sand and silt fractions after CBD treatment by the centrifugation method of Jackson (1975). The six contaminated soils had very similar clay mineral compositions. The X-ray diffraction patterns (XRD) of the contaminated soil clays were remarkably similar to those of the Fincastle and Henshaw clay samples. The XRD patterns of clay fractions from SP4-1A/2A and Henshow soils were shown in Fig. 4 as examples. The XRD after magnesium and ethylene glycerol solvation showed very weak 18-, 14-, 10-, 7-, and 3.34- $\AA$ peaks with other second order peaks. After heating $\mathrm{K}$ saturated samples to $550^{\circ} \mathrm{C}$, the 7- $\AA$ peak disappeared. The XRD results indicated that the clay fractions were composed of smectite, vermiculite, mica, kaolinite, and quartz. Swelling clays consisting of smectite and vermiculite were a minor component in the soils. Since clay minerals control many chemical and physical properties of soil, clay mineral composition could influence treatability of soils, dewatering after soil washing, and disposal of secondary waste. Since the clay mineral composition of all core samples was similar, these soil clays should respond about the same to decontamination treatments. 


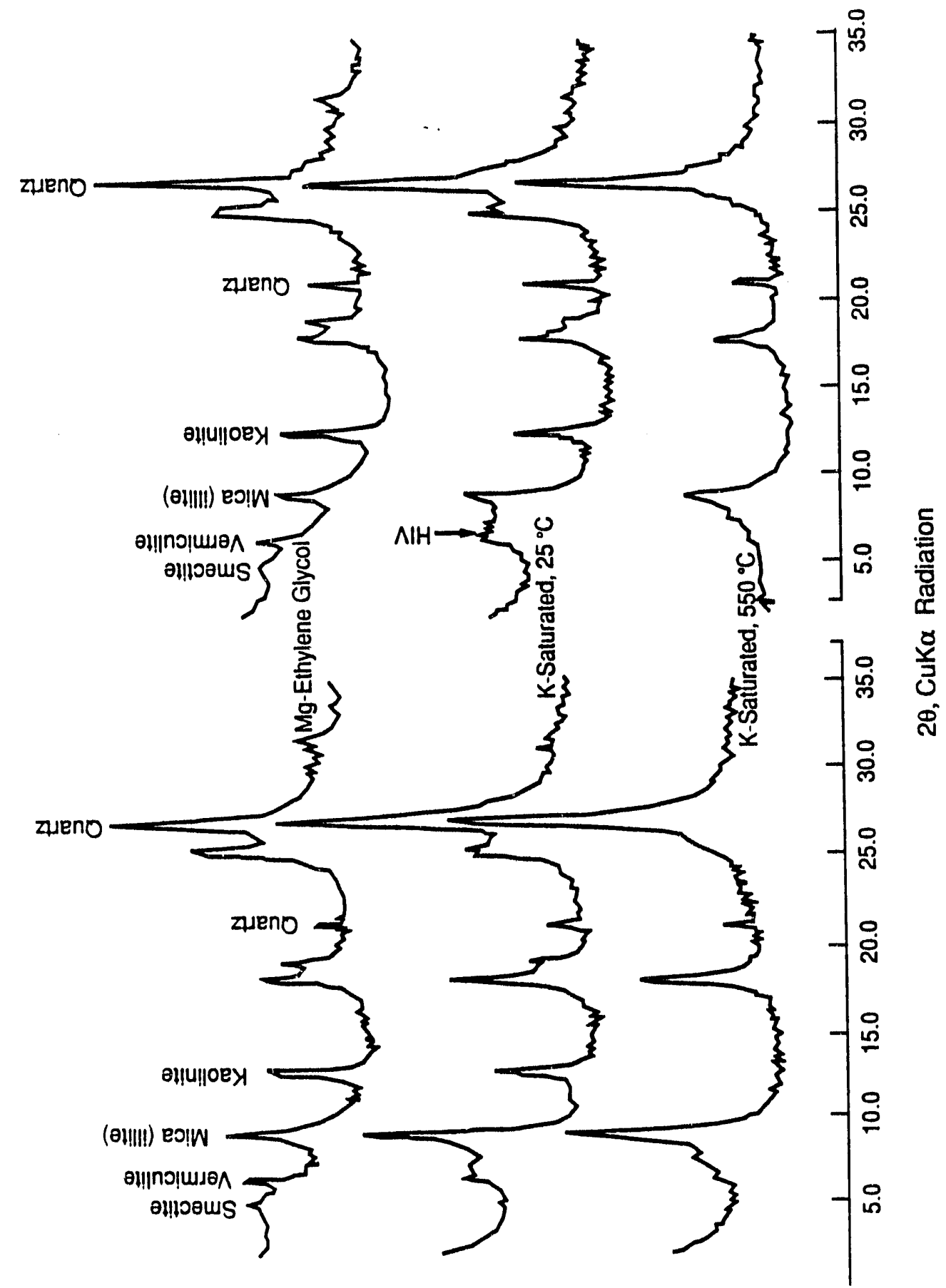

Figure 4. XRD of clay fractions of SP4-1A/2A and Henshaw soils 


\section{Chemical Leaching Experiments}

The chemical leaching experiments were conducted to provide general information to the Treatability Task Group. The mild acid ( $0.1 \mathrm{~N}$ nitric acid) treatment would remove uranium precipitates on the soil mineral surfaces and dissolve some uranium associated with carbonates. However, the mineral acid treatment was not effective because the contaminated soils contained too many limestone gravels (Table 17). The hydroxylamine hydrochloride treatment would remove uranium associated with manganese coatings in the contaminated soils. The nominal effectiveness of this treatment suggested that extraction of manganese would not have an effect on uranium leaching. Sodium hypochlorite is an effective oxidant for a reduced form of uranium. Oxidation of the reduced uranium would promote leaching by inducing complexation with soil carbonates. The experimental results showed some positive but minimal effects. EDTA is a well known chelating ligand for metals. The treatment was very effective for the SP4 soil sample but was not effective for the other soil samples. CBD treatment is a standard method for removing amorphous sesquioxides (iron and aluminum) in soils. As expected, considerable amounts of uranium (10 to $30 \%$ ) were removed by this treatment. The bicarbonate and citrate in the solution could be complexed with uranium when the sesquioxides were dissolved by the treatment. The citric acid and ammonium carbonate treatments were the most effective, particularly for the SP4, for removing uranium. Urnium in the soils might be dissolved from solid phase by the citric acid and then complexed as citrate. The excess carbonates in the ammonium carbonate solution would promote complexation of uranium in the contaminated soils.

\section{SUMMARY AND RECOMMENDATIONS}

The Phase I soil sampling and characterization task was established by the Characterization Group to obtain basic information related to soil properties and the nature of uranium contamination. The results of this preliminary investigation were intended for (1) the selection of contaminated soils for use in treatability studies, (2) the selection of a field demonstration area or areas within Operable unit 3, and (3) the preliminary screening of integrated decontamination technology. 


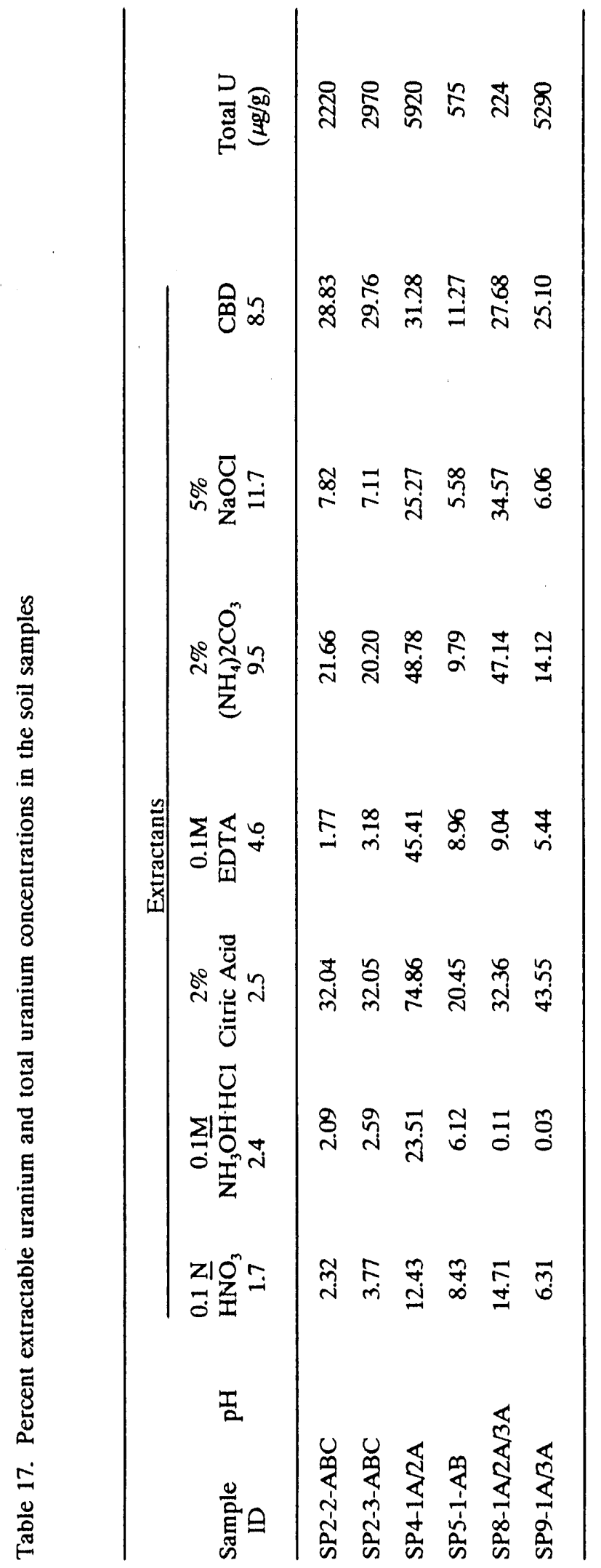


Ten soil sampling locations were selected from five different areas: Plant $2 / 3$ area, storage Pad Area, Decontamination Pad/Drum Baling Area, Plant 6 Area, and Incinerator Area (Figs. 1 and 2). After examining general soil properties such as $\mathrm{pH}$, texture, morphology, and radionuclide survey by gamma scanning, five sampling locations (SP2, SP4, SP5, SP8, and SP9) representing each area were selected for detailed characterization. Surface soil samples with varying depths were prepared for characterization because of a higher uranium contamination, except the SP2 location. Two subsurface soil samples were selected from SP2 core, one from 10 to 20 in. (SP2-2) and from 20 to $31 \mathrm{in.}$ (SP2-3). Two reference soils representing undisturbed plant area soils were also collected from about 1 to 2 miles west of Fernald Operation Site (Fig. 3).

\section{Selection of Contaminated Soils for Use in Treatability Studies and Demonstration Areas}

Three areas, Plant 2/3 represented by SP1 and SP2 samples, Plant 1 Drum Storage Area representing by SP3 and SP4 samples, and Incinerator Area representing SP9 and SP10 samples, have potential to be used for treatability studies. The other two areas, Decontamination Pad/Drum Baling Area and Plant 6 area investigated, are not good candidates because the uranium concentration is too low for technology evaluation and/or the depth of contamination is too shallow for excavation without mixing with uncontaminated soils. In addition, the presence of contaminated slag material in the Decontamination Pad/Drum Baling Area would be a negative element for the effectiveness of decontamination demonstration.

Plant 2/3 Area: The history of contamination, depth of contamination, and nature of contamination suggested that the area was contaminated by aqueous uranium waste. However, the characterization results indicated that silt and sand size fractions were the major uranium contributor in the soil. The microscopic analysis and density separation also indicated that some of the uranium in the soil was in particulate form having a density higher than $2.8 \mathrm{~g} / \mathrm{mL}$. Leaching experiment showed relatively low uranium extractabilty although the uranium particulates appeared as amorphous precipitate forms (Plates 1 and 2). EDX analysis showed that most uranium-containing particles also had calcium and phosphorous as elemental components. Since the contaminated zone had a fairly high 
content of slightly contaminated but easily cleaned limestone gravel, a combination of extraction and physical size separation treatment would achieve more than $60 \%$ of waste volume reduction.

Plant 1 Drum Storage Area: The area was suspected to be contaminated by uranium product spills. As expected, the nature of the contamination is very complex. More than $80 \%$ of uranium was associated with sand and silt fractions coprising about $74 \%$ of the soil. However, the citric acid and ammonium carbonate solutions were able to extract about 75 and $49 \%$ of uranium from the soil, respectively (Table 17). The uranium particles were associated with iron, calcium, phosphorous, and silicon (Plate 3). Others had only uranium (oxide or metallic ?) (Plate 4). Density-based separation was also successful in isolating uranium-containing heavy particles from the sand fraction (Table 16). This is an excellent candidate area for demonstration of decontamination technologies based on chemical extraction and density separation.

Incinerator Area: This area was suspected to have been contaminated by airborne uranium material. As expected, uranium-containing particles having different composition, shape, and sizes were in the soil samples collected from the area (Plates 9, 10, and 11). Chemical leaching of uranium by citric acid was moderately effective $(43 \%)$ but was not very effective by ammonium carbonate solution (14\%) (Table 17). Heavy liquid density separation was also moderately effective (Table 16). It will be a very difficult engineering challenge to remove uranium or reduce waste volume because the most abundant size fractions (sand and silt) had the most uranium (79\% of total uranium) in the soil.

\section{Preliminary Screening of Integrated Technology}

Preliminary leaching test results indicated that (1) citric acid dissolution/complexation and carbonate complexation were the most effective methods for removing adsorbed or leachable uranium in the contaminated soils, (2) oxidant and inorganic mineral acid were the least effective leachate solutions, (3) the amount of extracted uranium did not correlate with either total amounts of uranium in soils or in clay fractions. Therefore, chemical extraction alone cannot be expected to accomplish soil remediation. Particle size 
distribution and uranium distribution with particle size fractions suggested that simple size separation would not always be effective for waste volume reduction. However, densitybased separation showed some degree of success for removing uranium-containing particles. Therefore, the integrated technology to be developed should be based on both chemical extraction and physical separation technologies.

Characterization Group: (1) need more sampling and characterization to verify the preliminary investigation results (e.g., soil samples underneath structures); (2) should investigate on-going geochemical processes to evaluate decontamination impacts; (3) should establish sample preparation and analytical methods as a part of the QA procedure; and (4) should prepare evaluation protocol for the treatment effectiveness and secondary waste disposal technology.

Treatability Group: (1) technologies should be able to remove both particulate form and leachable forms of uranium in these soils, (2) proposed technologies should recycle leaching solution after removal of uranium, (3) should prepare several decontamination schemes reflecting the area specific conditions, and (4) decontamination products to be returned to the site should not include a carbonate source.

Excavation Group: (1) need development of a depth sensing remote control devise to remove the contaminated surface soils ( $<8$ in.).

Risk Assessment and Regulation Group: (1) need early establishment of a lower limit of uranium concentration for candidate soils and upper limit for treated soil to be returned to the field. 


\section{REFERENCES}

DOE. 1990. Draft Remedial Investigation Report for Operable Unit 3. Task 6 Report. Feed Material Production Center, Fernald, Ohio. FMPC-0306-2 Draft, U.S. Department of Energy, Oak Ridge Operations Office, Oak Ridge, Tennessee.

Drever, J. I. 1973. Preparation of oriented clay mineral specimens for X-ray diffraction analysis by a filter-membrane peel technique. Am. Mineral. 58:553-554.

Jackson, M. L. 1975. Soil Chemical Analysis-Advanced Course. 2nd ed. Published by the author, University of Wisconsin-Madison, Wisconsin.

Lee, S. Y., L. K. Hyder, and P. D. Alley. 1990. Microstructural and mineralogical characterization of selected shales in support of nuclear waste repository studies. Chapt. 58. In: Microstructure of Fine-Grained Sediments (R. H. Bennett et al.). Springer-Verlag. New York.

SCS. 1982. Soil survey of Hamilton County, Ohio. Soil Conservation Service. USDA.

Soil Survey Staff. 1975. Soil Taxonomy: A basic system of soil classification for making and interpreting soil surveys. USDA-SCS Agric. Handb. 436. U.S. Government Printing Office, Washington, D.C.

Tidwell's Memorandum. 1991. Integrated Technology Demonstration, Removal of Uranium Substances from Soils, Phase I Sampling Plan. K. R. Nuhfer File, WMCO:EMT(FIDS):91-097, June 19, 1991. Westinghouse Materials Company of Ohio, Fernald, Ohio. 
APPENDIX 

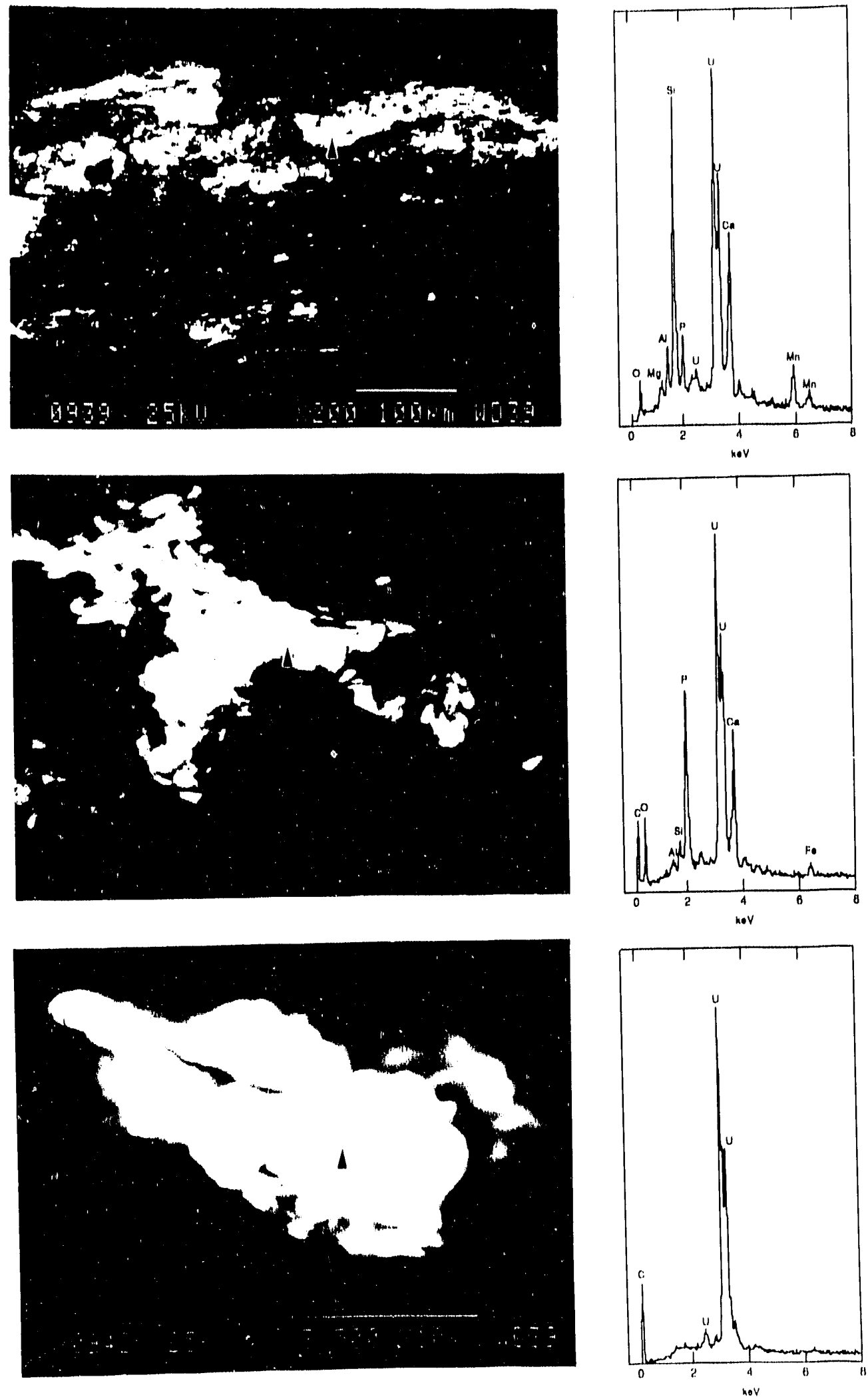

Plate 1. SEM and EDX of uranium-containing particles from SP2 soil sample. 

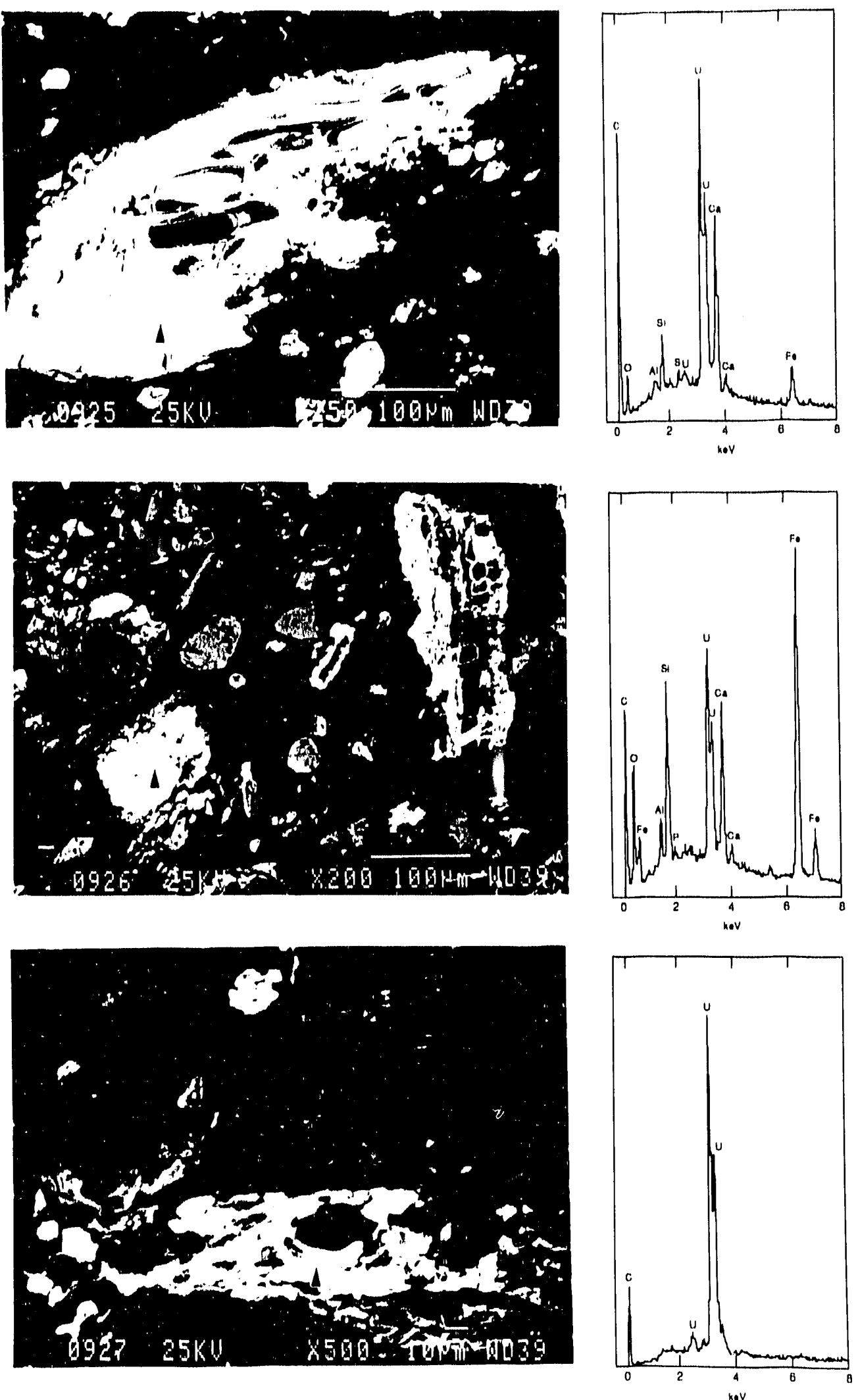

Plate 2. SEM and EDX of uranium-containing particles from SP4 soil sample. 
OANL.DWG 91.15125
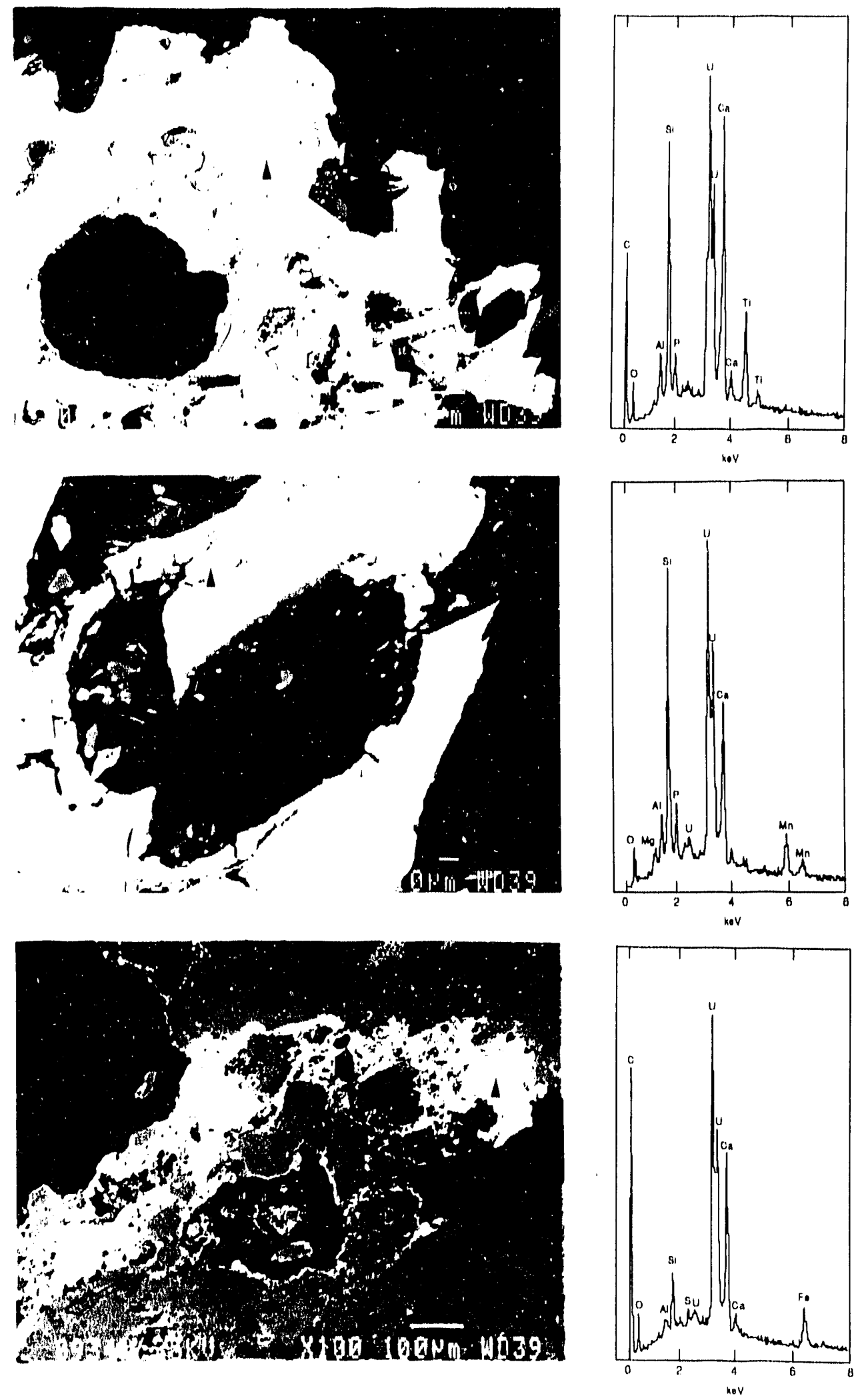

Plate 3. SEM and EDX of uranium-containing particles from SP5 soil sample. 


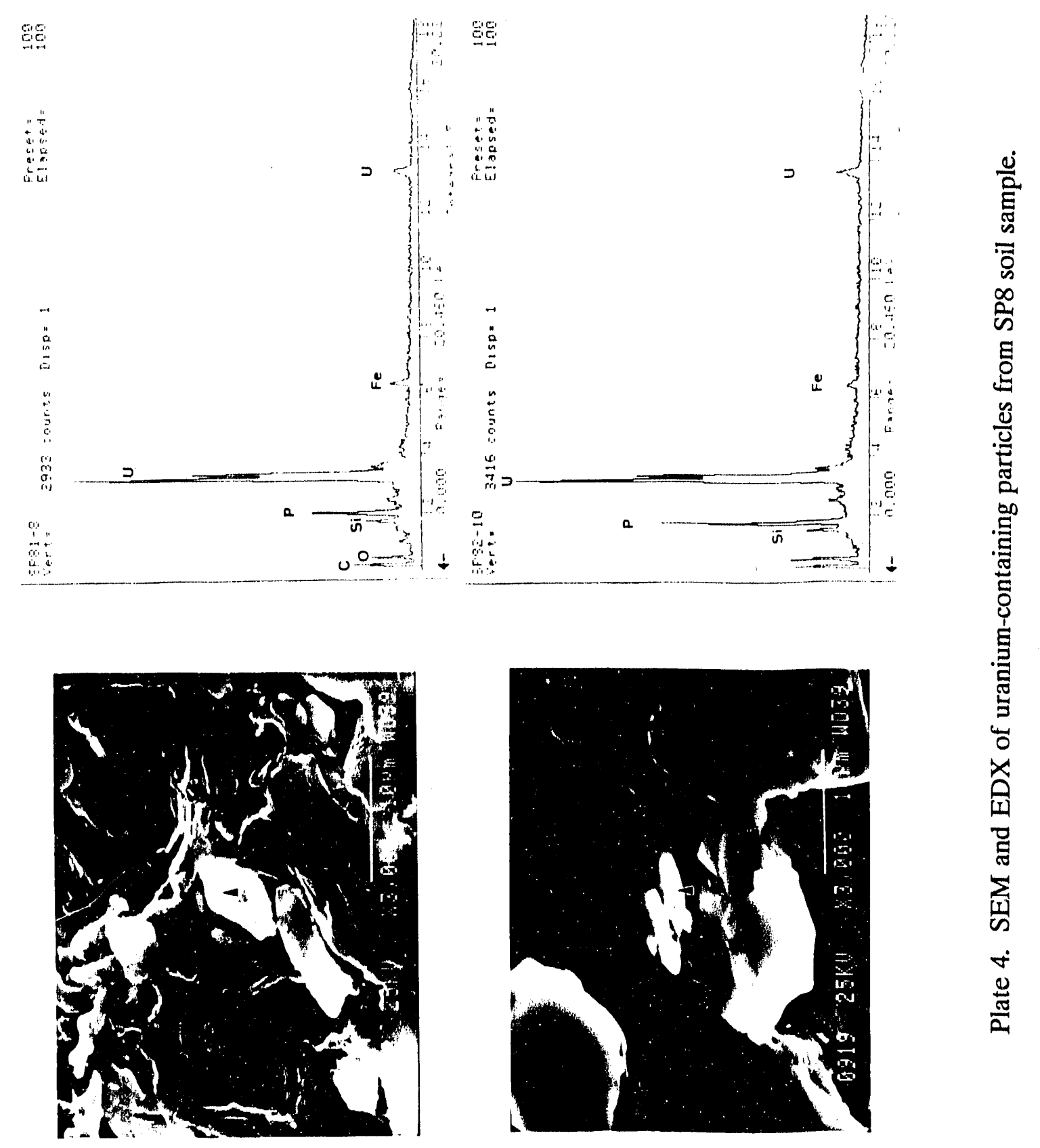




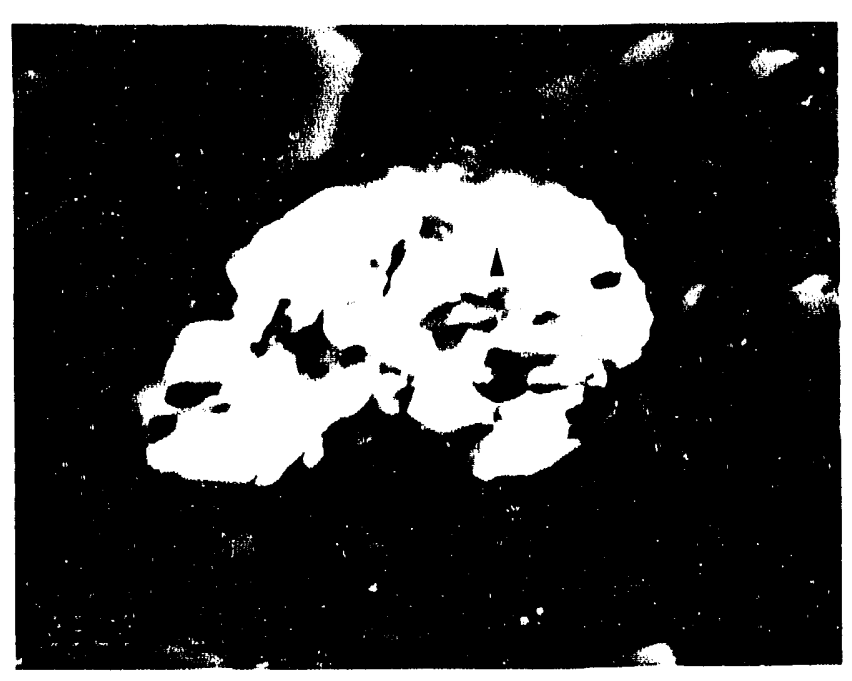

ORNL-DWG 91.15126
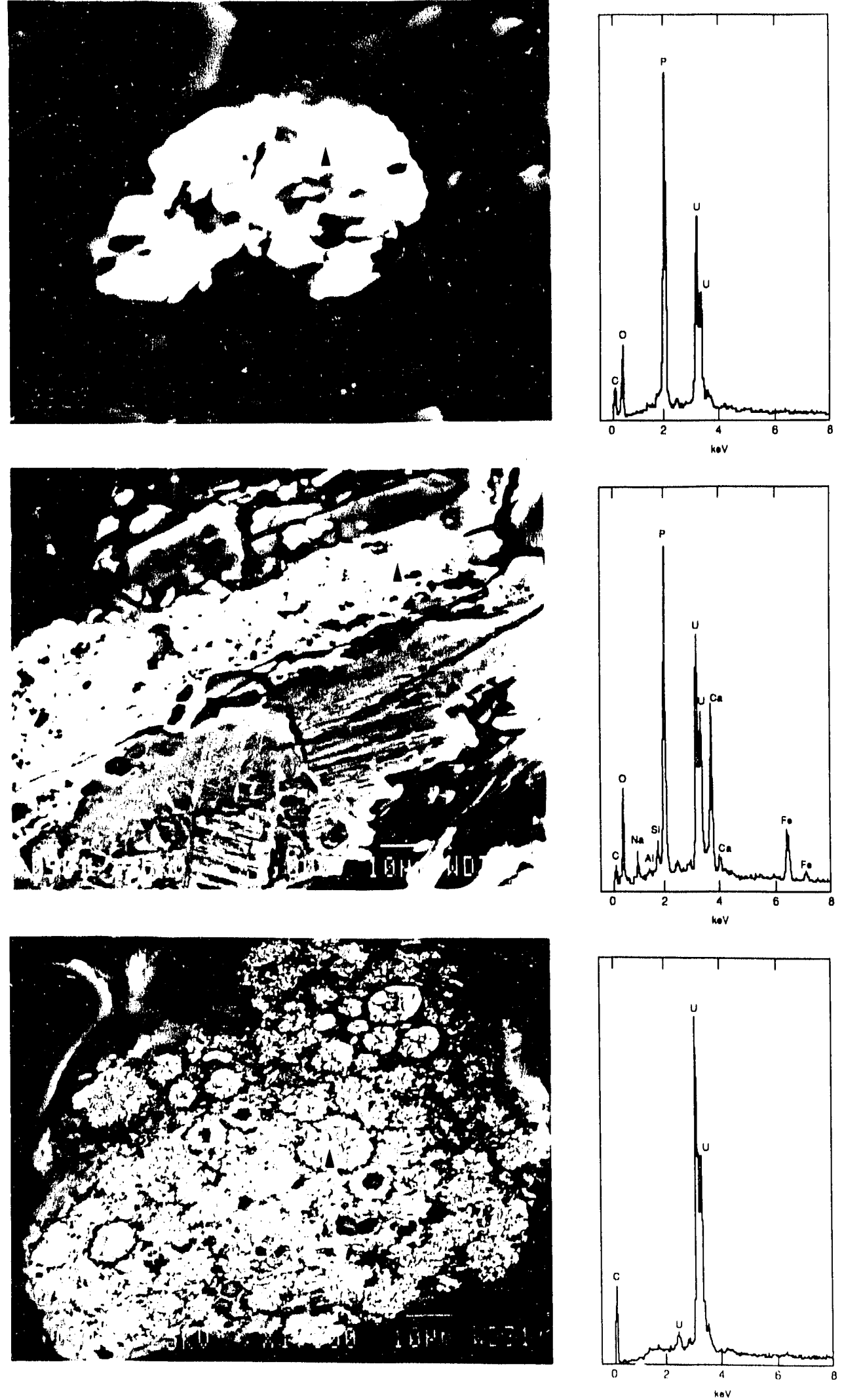

Plate 5. SEM and EDX of uranium-containing particles from SP9 soil sample. 


\section{INTERNAL DISTRIBUTION}

$\begin{aligned} \text { 1. } & \text { A. Q. Armstrong } \\ 2 . & \text { C. F. Baes } \\ 3 . & \text { L. D. Bates } \\ 4 . & \text { J. H. Cushman } \\ 5 . & \text { D. E. Fowler } \\ 6 . & \text { C. W. Francis } \\ 7 . & \text { C. W. Gehrs } \\ 8 . & \text { D. K. Halford } \\ 9 . & \text { S. G. Hildebrand } \\ \text { 10. } & \text { J. W. Koger } \\ 11 . & \text { P. Kanciruk } \\ 12-21 . & \text { S. Y. Lee } \\ 22 . & \text { D. B. Lloyd } \\ 23 . & \text { A. P. Malinauskas } \\ & \end{aligned}$
24-33. J. D. Marsh
34. D. E. Reichle
35. B. R. Rodgers
36. F. E. Sharples
37. D. S. Shriner
38. S. H. Stow
39. R. I. Van Hook
40. J. S. Watson
41. Central Research Library
42-56. ESD Library
57-58. Laboratory Records Dept.
59. Laboratory Records, RC
60. ORNL Patent Office

\section{EXTERNAL DISTRIBUTION}

61. O. B. Adams, 6120 South Gilmore Road, Fairfield, $\mathrm{OH} 45014$

62. R. B. Allen, DOE-FO, P. O. Box 398705, Cincinnati, OH 45239-8705

63. T. D. Anderson, U.S. Department of Energy, EM-551, 12800 Middlebrook Road, Germantown, MD 20874

64. J. A. Apps, Lawrence Berkeley Laboratory, University of California, Berkeley, CA 94720

65. L. Austin, Los Alamos National Laboratory, NMT-2, MS E501, P. O. Box 1663, Los Alamos, NM 87545

66. D. H. Bandy, TPO/AL, U.S. Department of Energy, P. O. Box 5400, Albuquerque, NM 87115

67. J. Berger, Office of Technology Integration, Westinghouse Hanford Co., P. O. Box 1970, MS LO-18, Richland, WA 99352

68. C. Bergren, Savannah River, Aiken, SC 29808

69. D. Berry, Department 6620, Sandia National Laboratory, Albuquerque, NM 87185-5800

70. J. Blakeslee, EG\&G Rock Flats, Inc., Technology Development, P. O. Box 464, Golden, CO 80402-0464

71. M. Bollenbacher, IT Corporation, 312 Directors Drive, Knoxville, TN 37923

72. D. J. Brettschneider, WEMCO/FEMP, P. O. Box 398704, Cincinnati, OH 45239-8704

73. R. Brodzinski, PNL, Battelle Boulevard, Richland, WA 99352

74. D. J. Carr, WEMCO/FEMP, P. O. Box 398704, Cincinnati, OH 45239-8704

75. R. A. Carrington, Plans \& Programs Division, MSE Inc., P. O. Box 3767, CDIF, Butte, Montana 59702 
76. D. J. Chaiko, Argonne National Laboratory, Chemical Technology Division, 9700 South Cass Avenue, Argonne, IL 60439-4837

77. T. R. Clark, WEMCO/FEMP, P. O. Box 398704, Cincinnati, OH 45239-8704

78. P. Colombo, Brookhaven National Laboratory, Building 703-50 Rutherford, Upton, NY 11973

79. L. A. Corathers, Battelle PNC, P. O. Box 999, Richland, WA 99352

80. J. Corones, AMES Laboratory, 329 Wilhelm Hall, Iowa State University, Ames, Iowa 50011

81. J. R. Craig, U.S. Department of Energy-FO, P. O. Box 398705, Cincinnati, OH 45239-8705

82. J. C. Cunnane, Argonne National Laboratory, 9700 South Cass Avenue, Argonne, IL 60439

83. H. Dugger, Daiser Engineers Hanford Co., Environmental Support Organization, P. O. Box 888, Richland, WA 99352

84. L. Dworjahyn, Westinghouse SRL, Building 779-2A, Aiken, SC 29808

85. L. Ebeling, REECO, P. O. Box 98521, Las Vegas, NV 89193

86. M. Elliot, EG\&G Idaho, Inc., P. O. Box 1625, Idaho Falls, ID 83415-3420

8\%. D. Emilia, Strategic Planning Department, Chem-Nuclear Geotech, P. O. Box 14000, Grand Junction, CO 81502-2567

88. R. B. Evans, Ph.D., Environmental \& Health Division, Reynolds Electrical \& Engineering Co., P. O. Box 98521, Las Vegas, NV 89193-8521

89. L. S. England Farmer, WEMCO/FEMP, P. O. Box 398704, Cincinnati, OH 45239-8704

90. C. J. Fermaintt, U.S. Department of Energy-FO, P. O. Box 398705, Cincinnati, OH 45239-8705

91. W. Fitch, U.S. Department of Energy, Idaho Field Office, 785 DOE Place, Idaho Falls, ID 83402

92. C. Frank, U.S. Department of Energy, EM-50, 6B-158/FORS, 1000 Independence Avenue, Washington, DC 20585

93. J. F. Franklin, Bloedel Professor of Ecosystem Analysis, College of Forest Resources, University of Washington, Anderson Hall (AR-10), Seattle, WA 98195

94. M. Fuhrmann, Brookhaven National Laboratory, Building 703M, Upton, NY 11973

95. A. Gatchett, RREL, 26 W. Martin Luther King Drive, Cincinnati, OH 45268

96. Richard Gay, Rockwell International, 6633 Canoga Avenue, Canoga Park, CA 91303

97. V. Gil, WEMCO/FEMP, P. O. Box 398704, Cincinnati, OH 45239-8704

98. R. Gilchrist, Technology Demonstration Programs, Westinghouse Hanford Co., P. O. Box 1970, MS L5-63, Richland, WA 99352

99. R. L. Glenn, Parsons, 6120 South Gilmore Road, Fairfield, OH 45014

100. J. Gnosse, WEMCO/FEMP, P. O. Box 398704, Cincinnati, OH 45239-8704

101. M. Gross, WEMCO/FEMP, P. O. Box 398704, Cincinnati, OH 45239-8704

102. Bimleshwar Gupta, Solar Thermal Electric Program, Solar Energy Research Inst., 1617 Cole Boulevard, Golden, CO 80401

103. K. Hain, U.S. Department of Energy, EM-55, 12800 Middlebrook Road, Germantown, MD 20874

104. J. Hall, U.S. Department of Energy, Nevada Field Office, P. O. Box 998518, Las Vegas, NV 89193-8518 
105. B. F. Harvey, 6120 South Gilmore Road, Fairfield, OH 45014

106. J. Haugen, U.S. Department of Energy, Chicago Field Office, 9800 South Cass Avenue, Argonne, IL 60439

107. K. Hayes, U.S. Department of Energy, EM-424, 12800 Middlebrook Road, Germantown, MD 20874

108. M. A. Heiskell, DOE/ORD, Waste Management Division (EW92), 200 Adminstration Road, Oak Ridge, TN 37831-8620

109. J. E. Helt, Ph.D., Director, Office of Waste Management Programs, 9700 South Cass Avenue, Argonne, IL 60439-4837

110. J. M. Hennig, U.S. Department of Energy, Richland Field Office, 825 Jadwin Avenue, P. O. Box 550, MS A.5-21, Richland, WA 99352

111. D. Herman, WEMCO/FEMP, P. O. Box 398704, Cincinnati, OH 45239-8704

112. William Holman, U.S. Department of Energy, San Francisco Field Office, 1333 Broadway, Oakland, CA 94612

113. J. P. Hopper, Technical Project Manager, Westinghouse Materials Co. of Ohio, P. O. Box 398704, MS 51, Cincinnati, OH 45239

114. G. M. Hornberger, Professor, Department of Environmental Sciences, University of Virginia, Charlottesville, VA 22903

115. J. Hyde, U.S. Department of Energy, EM-55, 12800 Middlebrook Road, Germantown, MD 20874

116. D. Jacoboski, WEMCO/FEMP, P. O. Box 398704, Cincinnati, OH 45239-8704

117. R. Jacobson, Ph.D., University of Nevada, Water Resources Center, Suite 1, 2505 Chandler Avenue, Las Vegas, NV 89120

118. S. James, RREL, 26 W. Martin Luther King Drive, Cincinnati, OH 45268

119. R. J. Janke, U.S. Department of Energy-FO, P. O. Box 398705, Cincinnati, OH 45239-8705

120. G. Y. Jordy, Director, Office of Program Analysis, Office of Energy Research, ER-30, G-226, U.S. Department of Energy, Washington, DC 20545

121. P. G. Kaplan, Division 6312, Sandia National Laboratory, Albuquerque, NM 87185

122. T. R. Kato, WEMCO/FEMP, P. O. Box 398704, Cincinnati, OH 45239-8704

123. K. Koller, EG\&G Idaho, Inc., P. O. Box 1625, Idaho Falls, ID 83402-3970

124. M. Krsitch, IT Corporation, 312 Directors Drive, Knoxville, TN 37923

125. D. Layton, Lawrence Livermore National Laboratory, P. O. Box 5507 (L-453), Livermore, CA 94550

126. D. Maiers, EG\&G Idaho, Inc., Technology Development Dept., P. O. Box 1625, Idaho Falls., ID 83415-3940

127. L. W. McClure, Westinghouse Idaho Nuclear Company, Inc., P. O. Box 4000, Idaho Falls, ID 83403-4000

128. T. McEvilly, 5OE-111, Lawrence Berkeley Laboratory, 1 Cyclotron Road, Berkeley, CA 94720

129. K. Merrill (Acting), EG\&G Idaho, Inc., P. O. Box 1625, Idaho Falls, ID 83415-3970

130. E. Merz, Waste Policy Institute, 12850 Middlebrook Road, Germantown, MD 20874

131. J. Mohiuddin, BDM Int., 12850 Middlebrook Road, Germantown, MD 20874

132. J. O. Moore, TPO, U.S. Department of Energy, Oak Ridge Operations Waste Management, P. O. Box 2001, Oak Ridge, TN 37831-8620

133. D. Morris, LANL-INC-4, MS C346, P. O. Box 1663, Los Alamos, NM 87545 
134. H. D. Murphy, ET-AET, Los Alamos National Laboratory, MS D446, Los Alamos, NM 87545

135. M. Nickelson, HAZWRAP, P. O. Box 2003, Oak Ridge, TN 37831-7606

136. T. Noble, Center for Advanced Technology Development, Iowa State University, Ames, IA 50011

137-139. K. Nuhfer, WEMCOP/FEMP, P. O. Box 398704, Cincinnati, OH 45239-8704

140. R. Olexsey, RREL, 26 Martin Luther King Dr., Cincinnati, OH 45268

141. R. H. Olsen, Vice President for Research, University of Michigan, Medical Science Building II, \#5605, 1301 East Catherine Street, Ann Arbor, MI 48109-0620

142. M. O'Rear, U.S. Department of Energy, Savannah River Field Office, RFD \#1, Building 703A, Room E208 North, P. O. Box A, Aiken, SC 29802

143. A. Patrinos, Acting Director, Environmental Sciences Division, Office of Health and Environmental Research, ER-74, U.S. Department of Energy, Washington, DC 20585

144. R. W. Perkins, PNL, Battelle Boulevard, Richland, WA 99352

145. D. L. Perry, Lawrence Berkeley Laboratory, University of California, Berkeley, CA 94720

146. M. Peterson, Battelle Pacific NW Laboratory, P. O. Box 999, MSINP7-41, Richland, WA 99352

147. F. Poucher, Energy Programs \& Advanced Planning, P. O. Box 1449-D/6222, T038, 6633 Canoga Avenue, Canoga Park, CA 91304

148. L. Rogers, EG\&G/EM, P. O. Box 1812, Las Vegas, NV 89125

149. R. R. Ryan, LANL-INC-4, MS C346, P. O. Box 1663, Los Alamos, NM 87545

150. J. Sattler, WEMCO/FEMP, P. O. Box 398704, Cincinnati, OH 45239-8704

151. P. A. Saxman, TPO/AL, U.S. Department of Energy, P. O. Box 5400, Albuquerque, NM 87115

152. A. Schilk, PNL, Nuclear Chemistry Department, Battelle Boulevard, Richland, WA 99352

153. J. Schnoor, 1134 Engineering Building, University of Iowa, Iowa City, Iowa 52242

154. J. Schwing, WEMCO/FEMP, P. O. Box 398704, Cincinnati, OH 45239-8704

155. R. S. Shirley, WEMCO/FEMP, P. O. Box 398704, Cincinnati, OH 45239.8704

156. S. C. Slate, Pacific Northwest Laboratory, MSIN KI-25, Office of Environmental Tech., P. O. Box 999, Richland, WA 99352

157. R. Snipes, Martin Marietta-HAZWRAP, P. O. Box 2003, Oak Ridge, TN 37831-7606

158. S. Spence, Kaiser Engineering, MS E6-22, P. O. Box 888, Richland, WA 99352

159. R. Stead, WEMCO/FEMP, P. O. Box 398704, Cincinnati, OH 45239-8704

160. J. L. Steele, P.E., Waste Environmental Remediation Programs, Savannah River Site, SRL, 733A, A208, Aiken, SC 29802

161. S. Stein, Deputy General Manager, Environmental Management Organization, Pacific Northwest Division, 4000 N.E. 41st Street, Seattle, WA 98105

162. K. Stevenson, U.S. Department of Energy, 376 Hudson Street, New York, NY 10014-3621

163. R. S. Siiger, Waste Technology Development, EG\&G Idaho, Inc., P. O. Box 1625, Idaho Falls, ID 83415-3940

164. T. M. Sullivan, Brookhaven National Laboratory, Building 830, Upton, NY 11973

165. R. E. Swatzell, HAZWRAP, P. O. Box 2003, Oak Ridge, TN 37831-7606 
166. J. Throckmorton, ASI, P. O. Box 475, Ross, OH 45061-0475

167. V. C. Tidwell, Sandia National Laboratory, MS 6315, P. O. Box 5800, Albequerque, NM 87185

168. J. Tipton, Assistant Operations Manager, Remote Sensing Laboratory, P. O. Box 1912, MS D-12, Las Vegas, NV 89125

169. A. E. Torma, EG\&G Idaho, Inc., P. O. Box 1625, Idaho Fall, ID 83415-3940

170. L. D. Tyler, Sandia National Laboratory, Division 6621, Box 5800, Albuquerque, NM 87185

171. R. Tyler, U.S. Department of Energy, Rocky Flats Office, DOE Building 116, Golden, CO 80402-0928

172. C. L. Valle, Allied Signal Aerospace, Kansas City Plant, P. O. Box 419159, D/272, FV43, Kansas City, KS

173. E. M. Van Feckhout, Los Alamos National Laboratory, P. O. Box 1663, Los Alamos, NM 87545

174. G. Voelker, U.S. Department of Energy, EM-55, 12800 Middlebrook Road, Germantown, MD 20874

175. T. L. Walton, Westinghouse SRC, SRL, P. O. Box 616, Aiken, SC 29802

176. P. Wichlacz, EG\&G Idaho, Inc., P. O. Box 1625, MS 3940, Idaho Falls, ID 83415

177. F. J. Wobber, Environmental Sciences Division, Office of Health and Environmental Research, ER-74, U.S. Department of Energy, Washington, DC 20585

178. S. Wolinsky, ASI, P. O. Box 475, Ross, OH 45061-0475

179. J. L. Yow, P. O. Box 808, 7000 East Avenue, MS L-207, Livermore, CA 94550

180. C. Zeh, Morgantown Energy Technology Center, 3610 Collins Ferry Road, Morgantown, WV 26507-0880

181. Office of Assistant Manager for Energy Research and Development, Oak Ridge Operations, P. O. Box 2001, U.S. Department of Energy, Oak Ridge, TN 37831-8600

182-191. Office of Scientific and Technical Information, P. O. Box 62, Oak Ridge, TN 37831 

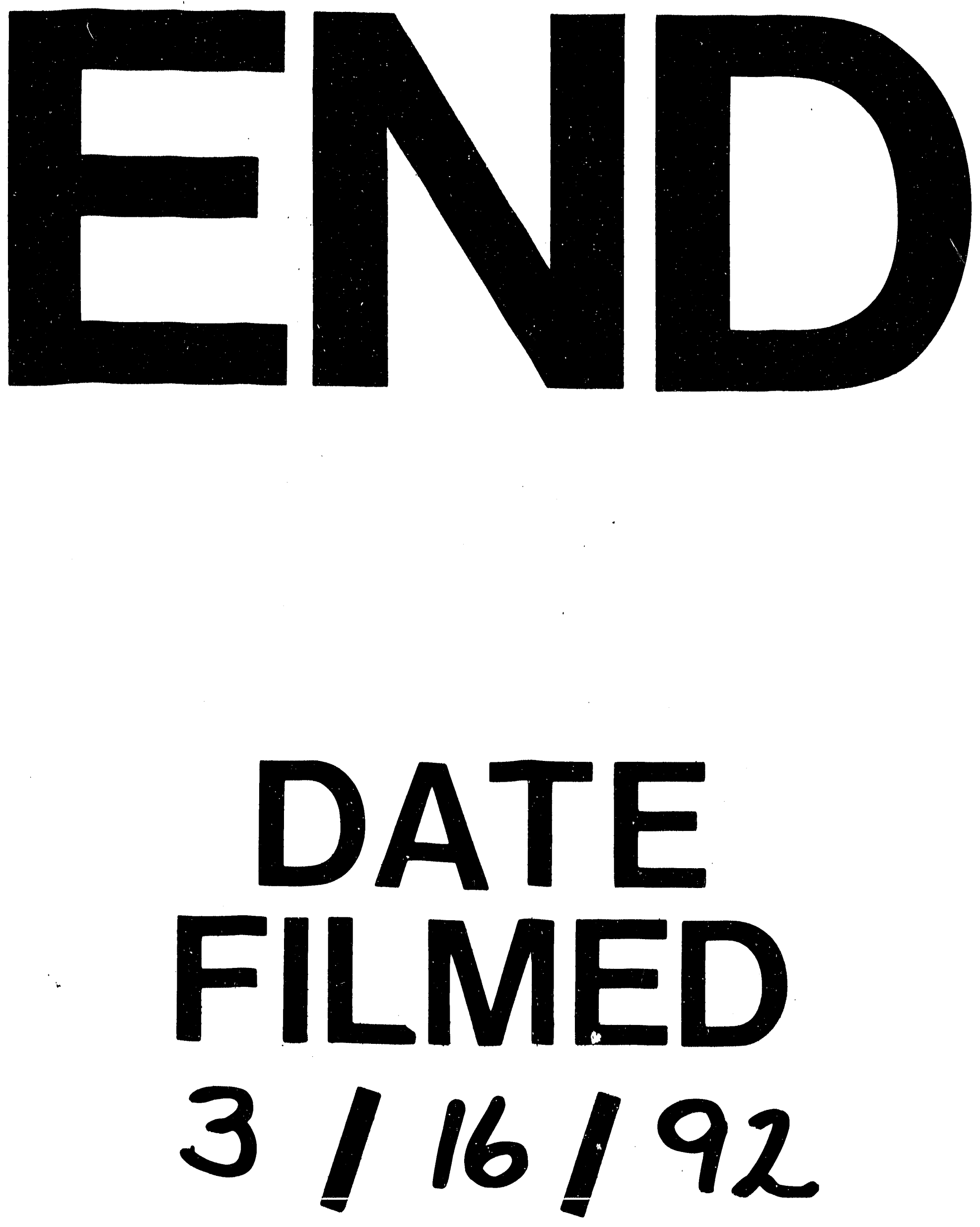
